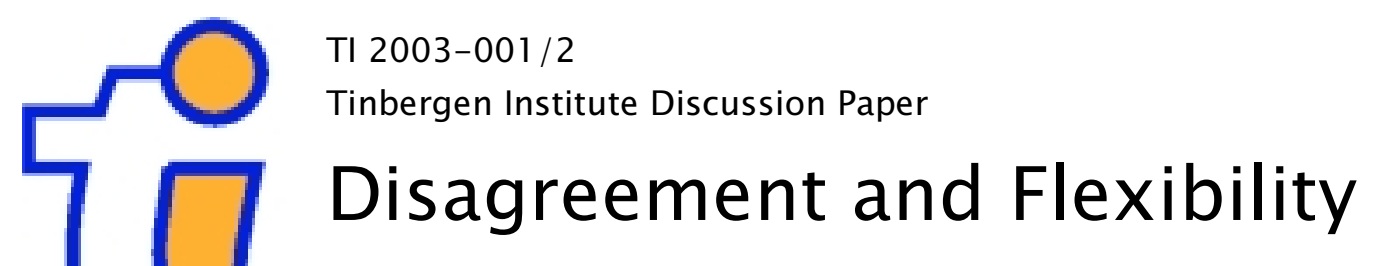

Arnoud W.A. Boot ${ }^{1}$

Anjan V. Thakor ${ }^{2}$

1 Faculty of Economics and Econometrics, University of Amsterdam, and Tinbergen Institute, 2 University of Michigan Business School. 
Tinbergen Institute

The Tinbergen Institute is the institute for economic research of the Erasmus Universiteit Rotterdam, Universiteit van Amsterdam and

Vrije Universiteit Amsterdam.

Tinbergen I nstitute Amsterdam

Keizersgracht 482

1017 EG Amsterdam

The Netherlands

Tel.: +31.(0)20.5513500

Fax: $\quad+31 .(0) 20.5513555$

Tinbergen Institute Rotterdam

Burg. Oudlaan 50

3062 PA Rotterdam

The Netherlands

Tel.: $\quad+31 .(0) 10.4088900$

Fax: $\quad+31 .(0) 10.4089031$

Most TI discussion papers can be downloaded at

http://www.tinbergen.nl 
First Draft, June 2002

This Draft, November 2002

\section{DISAGREEMENT AND FLEXIBILITY: A THEORY OF OPTIMAL SECURITY ISSUANCE AND CAPITAL STRUCTURE}

by

Arnoud W.A. Boot ${ }^{*}$ and Anjan V. Thakor ${ }^{* *}$

Acknowledgments: We thank Christa Bouwman, Josh Coval, Kathleen Fuller, Amrita Nain, Radhakrishnan Gopalan, Andrei Shleifer and participants at the 2002 Colorado Summer Conference for helpful comments.

\footnotetext{
${ }^{*}$ University of Amsterdam

** University of Michigan Business School
} 


\title{
DISAGREEMENT AND FLEXIBILITY: A THEORY OF OPTIMAL SECURITY ISSUANCE AND CAPITAL STRUCTURE
}

\begin{abstract}
In this paper we introduce flexibility as an economic concept and apply it to the firm's security issuance decision and capital structure choice. Flexibility is the ability to make decisions that one thinks are best even when others disagree. The firm's management values flexibility because it allows management to make decisions it believes are best for shareholders without being blocked by dissenters. The amount of flexibility management has at any point in time depends on how the firm is financed. Debt offers little flexibility relative to equity. However, the flexibility offered by equity depends on the extent to which shareholders are inclined to agree with management's strategic choices. Equity offers the greatest flexibility when the propensity for shareholder agreement is the highest. It turns out that the firm's stock price is also increasing in shareholders' propensity to agree with management. Thus, the flexibility benefit of equity is high only when the share price is high. The firm's optimal security-issuance choice trades off the flexibility benefit of equity against the now-familiar debt tax shield, and the firm's capital structure is the consequence of a sequence of past security-issuance choices. The strongest implication of this theory of capital structure evolution is that optimal capital structure is essentially dynamic, and depends on the firm's stock price, implying that firms issue equity when stock prices are high and debt when stock prices are low. The theory explains many stylized facts that fly in the face of existing capital structure theories and also generates new testable predictions. Moreover, the theory can rationalize the use of debt in the absence of taxes, agency costs or signaling considerations.
\end{abstract}




\section{DISAGREEMENT AND FLEXIBILITY: A THEORY OF OPTIMAL SECURITY ISSUANCE AND CAPITAL STRUCTURE}

\section{INTRODUCTION}

People often disagree on the optimal course of action even when faced with exactly the same information. Two faculty members may attend a recruiting seminar and disagree on the candidate's research potential. Two firms looking at the same market research data may reach opposite conclusions about whether a new product should be introduced. The Board of Directors may disagree with the Chief Executive Officer (CEO) about the firm's strategic direction even when the CEO has provided the Board with all of the information on which the CEO's decision is predicated. A recent example of this is the firing of media giant Bertelsmann's CEO Thomas Middelhoff on July 28, 2002. The company explained that Middelhoff stepped down because of "differences of opinion... on the future strategy of Bertelsmann." In this paper we examine how the possibility of such disagreement leads management to value decisionmaking flexibility and thereby affects the firm's capital structure.

There are numerous reasons why the communication of a common information set may not lead to consensus about the optimal course of action. One is non-uniform priors, with insufficient time for objective information to be exchanged to permit convergence to a common posterior belief (e.g. Allen and Gale (1999) and Morris (1995)). Another reason may be unequal information-processing capabilities or levels of "attentiveness" (Hirshleifer, Lim and Teoh (2002)). A third possibility is that some agents may react to pure noise as if it were information, whereas others may not, so that there may be extraneous signals in addition to the common information being presented that different agents process differently. For example, some people

\footnotetext{
${ }^{1}$ Kessler reported, "But there were reports that the executive and the board of the closely held media giant clashed over his push to take the company's shares public. Bertelsmann had planned a stock offering in 2005 to raise money. Now that could be postponed or cancelled", in "Another Media Exec Ousted: Bertelsmann CEO", USA Today, Section B, July 29, 2002.
} 
are excessively sensitive to the way information is presented, which diminishes their focus on the content of the information (Russo and Shoemaker (1990)). Kandel and Pearson (1995) have shown that trading volume around public information announcements can be best understood within a framework in which agents interpret the same information differently. A fourth possibility is overconfidence on the part of one or more of the agents involved (e.g. Daniel, Hirshleifer and Subrahmanyam $(1998,2001)$ ). A fifth is differences in ideology (Mullainathan and Shleifer (2002)). Numerous other possibilities have been discussed in psychology, such as a propensity for viewing decisions as unique and ignoring historical data that could lead to beliefs convergence (Kahneman and Lovallo (1993)), different types of intuition (Clarke and Mackaness (2001)) and differences in personality types (Stumpf and Dunbar (1991)). ${ }^{2}$ Whatever the reason for disagreement, such situations are interesting when they involve disagreement between a decisionmaker and those who must "endorse" the decision. Examples would be a bank that needs regulatory approval to open a new branch or acquire another bank, a CEO who needs Board approval to launch a new strategy like expanding into new markets, or a firm that needs its creditors' permission to do something proscribed by its covenants.

Faced with the potential for such disagreement, the decisionmaker will value the ability to decide over the objections of those who disagree. We refer to this ability as "flexibility". Managers sometimes call this "elbow room", the ability to change operating direction when circumstances change. How much elbow room is available may depend on many factors, one of which is its financial leverage. A firm with high financial leverage is likely to have less flexibility than a firm with low financial leverage, if for no other reason than restrictive debt covenants. ${ }^{3}$ Management that values flexibility will take this into account along with factors like

\footnotetext{
${ }^{2}$ See Boot and Thakor (2002) for an extended discussion.

${ }^{3}$ Various papers have shown that, in periods of economic distress, debt can significantly hamper the firm's economic performance (see, for example, Opler and Titman (1994)).
} 
taxes in determining the firm's source of financing and capital structure. A study of the explicit tradeoffs involved therefore seems potentially promising. Our goal is to explore how flexibility considerations affect a firm's security-issuance decision and its capital structure.

This goal is motivated in part by anecdotal evidence that some firms appear to have consistently underutilized leverage. For example, companies like Cisco and Microsoft have for years operated with no long-term debt and significant excess liquidity. Reuters has had a long history of zero to negligible financial leverage. Similarly, large U.S. bank holding companies have maintained capital levels significantly above the regulatory minimum for the past several years (see Flannery and Rangan (2002)). What value do these firms see in foregoing the taxshield advantages of debt? It is difficult to use the standard agency-cost argument when leverage is in the neighborhood of zero, nor does signaling offer much help. Intuition suggests that the desire for strategic and operating flexibility may drive this behavior.

There are other gaps between existing theories and stylized facts. Existing theories derive an optimal capital structure by relaxing the key assumptions of the original Modigliani and Miller $(1958,1963)$ theory. In particular, the signaling approach predicts that more valuable firms use more debt (Ross (1977)), the agency approach says that firms with greater assetsubstitution moral hazard opportunities use less debt (Jensen and Meckling (1976)), the taxshield hypothesis suggests less debt usage by firms with more non-debt tax shields (DeAngelo and Masulis (1980)), and the desire to control abuses related to free cash flow (Jensen (1986)) as well as otherwise discipline management (Grossman and Hart (1982)) leads to less equity and more debt. All of these theories imply that the firm strives for an optimal capital structure, so that as the market value of its equity changes, capital structure adjusts as well. ${ }^{4}$

\footnotetext{
${ }^{4}$ There are also other theories of capital structure, e.g. Jaggia and Thakor (1994) in which capital structure interacts with labor market considerations, Zwiebel (1996) in which managerial entrenchment motives determine capital structure, and Brander and Lewis (1986) in which capital structure affects strategic product-market competition.
} 
More specifically, these theories predict that an increase in stock prices - which lowers the debt to equity ratio in market value terms - should lead firms to borrow more to bring their capital structures back in line with their respective optima. But the facts say otherwise. Firms tend to issue equity rather than debt when equity valuations are high (see Asquith and Mullins (1986), Korajczyk, Lucas and McDonald (1991), Jung, Kim and Stulz (1996), and Marsh (1982)). That is, firms issue equity to apparently exploit market timing, ${ }^{5}$ which is most graphically illustrated in the survey evidence of Graham and Harvey (2001) which indicates that CFOs considered equity market prices as more important than most other factors considered in the decision to issue common stock and debt.

It appears then that the security-issuance decision is not driven by the desire to stay at or move to a desired capital structure. Instead, it seems to be driven by the level of the firm's stock price, and capital structure is then the outcome of this market timing. A substantial empirical boost to this heuristic argument was provided by Baker and Wurgler (2002), who found that market timing has large, persistent effects on capital structure. They conclude, "It is hard to explain this result within traditional theories of capital structure.... In our opinion, a simple and realistic explanation for the results is that capital structure is the cumulative outcome of attempts to time the equity market." 6 They go on to speculate that the best way to explain such markettiming behavior may be to assume that managers think investors are irrational and raise equity when the cost of equity is perceived to be low.

These findings raise an obvious question: is it possible to develop a coherent theory of the security issuance decision with rational agents that has capital structure implications and predictions consistent with the stylized facts?

\footnotetext{
${ }^{5}$ Empirical evidence also suggests that firms tend to issue equity at times when investors are highly enthusiastic about earnings prospects. See Loughran and Ritter (1997), Rajan and Servaes (1997), Teoh, Welch and Wong (1998a, 1998b), and Dennis and Sarin (2001).

${ }^{6}$ See p. 3 in Baker and Wurgler (2002).
} 
We develop a theory of the firm's security issuance and capital structure decisions based on the value the manager attaches to flexibility. We view equity as a (relatively) flexible contract and debt as an (relatively) inflexible contract. ${ }^{7}$ The manager's tradeoff is simple. He values debt because the associated debt tax shield lowers his cost of capital. He values equity because it offers him greater flexibility. Our analysis also accommodates the fact that equity is only a relatively more flexible contract than debt and that there may be instances in which shareholders, who disagree with the CEO, end up blocking the CEO's action, thereby denying him ex post the flexibility he associated with equity ex ante.

Our model captures the tradeoff between flexibility and tax benefits as follows. The firm faces an investment opportunity that is potentially subject to disagreement between the manager and investors. This is not an issue of the manager possessing private information that investors don't have. It is simply a matter of external financiers disagreeing with the manager about project value. Hence, it is not a problem that incentive contracting can readily solve either, since the manager truly believes he is maximizing firm value.

The investment opportunity in our model is characterized by two parameters: the quality of the opportunity (opportunity quality), and the probability that others will agree with the manager that it is a good opportunity (potential agreement). While the opportunity quality is common knowledge, only the market (in the aggregate) may know the agreement parameter, so the manager may have to infer it from his firm's stock price. Thus, for any value of the manager's assessment of the opportunity quality, the higher the stock price, the higher is the agreement parameter because investors value the firm more highly when they perceive a lower probability the manager will take actions that they will disapprove of. Similarly, the lower is the

\footnotetext{
${ }^{7}$ In extensions of the framework developed here, one could distinguish among different types of debt based on flexibility. For example, bank debt may be considered more flexible than public debt due to its easier renegotiability (see Berlin and Mester (1992)).
} 
stock price, the lower is the potential agreement parameter. So the manager finds equity most attractive when the price of his own firm's stock is high and opposition from shareholders least likely. When the potential disagreement is high, opposition from shareholders is likely and debt, which will also lead to disagreement, may be preferred given its tax advantages.

Our theory has implications for the literature on optimal security issuance as well as that on optimal capital structure. The paper most relevant to ours on optimal security issuance is Myers and Majluf (1984). That paper generates a "pecking order" of securities based on the assumption that there is asymmetric information, and the firm's management has payoff-relevant information that is superior to that of investors. Consequently, the firm prefers to first finance with internal cash, then debt and then equity. Myers and Majluf's (1984) pecking-order theory, as it stands, is neither consistent nor inconsistent with firms choosing to issue equity when stock prices are high. ${ }^{8}$ By contrast, our model produces a direct prediction that equity will be issued when stock prices are high and debt will be issued when stock prices are low.

The capital structure implications of our theory are striking. The recent empirical findings that capital structure seems to be driven by stock prices and returns have led to the conclusion that firms do not seem to behave as if they have a target capital structure (see, for example, Baker and Wurgler (2002) and Welch (2002)). Our theory reveals that there is no inconsistency between firms having target capital structures and these capital structures being driven by the firms' stock prices. This is because the firm's optimal capital structure is dynamic,

\footnotetext{
${ }^{8}$ Baker and Wurgler (2002) suggest that this empirical finding of theirs is consistent with a dynamic version of Myers and Majluf (1984) in which one assumes that the amount of asymmetric information is lower when the firm's market-to-book ratio is higher. However, it is just as plausible to assume that the amount of asymmetric information is higher when market-to-book ratios are higher. For example, stock prices may be driven higher when growth opportunities are greater relative to assets in place, and the informational gap between management and insiders is likely to widen during such periods. Besides, the relationship between the amount of asymmetric information and market-to-book ratios is outside the Myers and Majluf (1984) model, so if consistency of that model with the empirical evidence rests on a specific assumption about that relationship, then the model becomes virtually impossible to refute empirically. In other words, in another time period or in a country other than the U.S., if firms were to issue equity when market-to-book ratios were low, one could argue that too is consistent with Myers and Majluf (1984) under the assumption that informational asymmetries are smaller when market-to-book ratios are lower.
} 
varying (continuously) with its stock price. While our analysis assumes debt has a tax advantage, we also show that debt can be valuable to the firm's shareholders even if there are no taxes, agency costs or signaling considerations because it can allow the shareholders to reduce disagreement between them and the manager. ${ }^{9}$ This brings to light a previously-unexplored role of debt as a "flexibility-limiting" device. In addition to these results, our flexibility theory of capital structure generates numerous testable predictions.

The theoretical paper most closely related to ours is Zwiebel's (1996) interesting analysis. In his model, the manager enjoys an exogenous control benefit and wants to keep his job. He can invest in either a good or a bad project, and his "type" determines the probability that he will receive a good project. The key problem is: how do you keep the manager from investing in a bad project when no good projects are available? It is assumed that the manager's type is common knowledge, so he faces the threat of a takeover and the concomitant loss of control rents if his type is low enough. To cope with this threat, the manager must precommit to not invest in the bad project. He does this by issuing debt because debt amplifies the impact of the bad project on the probability of bankruptcy, with the manager losing control rents in the event of bankruptcy. With sufficient debt, the manager's precommitment to eschew the bad project is credible. Since the firm's stock price is higher when the probability of a good project is higher, the importance of debt as a disciplining device diminishes as the stock price rises, leading to the implication that leverage decreases when stock prices are high.

The similarity between Zwiebel's analysis and ours is that both imply a negative relationship between leverage and stock prices. The factors driving this and other results in the two models are entirely different, however. The key differences are as follows. First, managerial utility maximization determines capital structure in Zwiebel's model, whereas

\footnotetext{
${ }^{9}$ That is, a tax advantage to debt is necessary to ensure that the manager will ever use debt, but it is unnecessary for the shareholders to want debt to be issued.
} 
shareholder value maximization determines capital structure in ours. Second, Zwiebel's theory of capital structure is driven by the disciplinary role of intermediate levels of debt financing in the face of bankruptcy costs. Our focus is on the value of equity in providing management with flexibility to maximize shareholder wealth in the face of disagreement. Thus, ours is an "equitycentered" theory of capital structure, whereas Zwiebel's is "debt-centered". Finally, our model generates a rich set of results without any agency problem between management and shareholders. Additional differences - such as the security-issuance announcement effects predicted by our model - become evident when we discuss our empirical predictions.

The rest of the paper is organized as follows. In Section II we develop the application of flexibility to the equity issuance decision and discuss its capital structure implications. Section III contains the analysis. Section IV discusses the testable predictions of the analysis. Section V concludes. All proofs are in the Appendix.

\section{THE ECONOMIC SETTING: DISAGREEMENT, FLEXIBILITY AND SECURITY ISSUANCE}

In this section we describe the model, explain how disagreement may arise and what flexibility means in that setting, and then examine the firm's security issuance decision.

\subsection{Model Description}

Preferences and Time Line: There are four points in time and all agents are risk neutral. At $\mathrm{t}=0$, the firm has existing assets in place and knows that an investment opportunity may arrive at $t=1$. The firm is all-equity financed at $t=0$, but its capital structure may be altered by its security-issuance decision at $\mathrm{t}=1$. The firm's stock price at $\mathrm{t}=0$ will reflect the market's assessment of the firm's future prospects, i.e. the investment opportunity that may arrive at $t=1$. At $\mathrm{t}=1$, the firm sees whether the new investment opportunity is available. If the opportunity is unavailable, no securities are issued. If it is available, the firm decides whether to issue debt or 
equity. Although funds are raised through this security issuance at $t=1$, the actual investment in the project is made only at $\mathrm{t}=2 .{ }^{10}$ Payoffs are realized at $\mathrm{t}=3$. The corporate income tax rate on payoffs at $t=3$ is $\tau \in(0,1)$. We set the discount rate equal to zero.

Project Investments and Payoffs: At $\mathrm{t}=0$ the firm has existing activities that will produce a deterministic output at $t=3$. We normalize this output and let it equal zero. In this way, the pricing of the securities will reflect only the firm's investment opportunity.

At $t=1$ a new investment opportunity arrives with probability $\theta$ which was common knowledge at $\mathrm{t}=0$. This common knowledge assumption means that there is no disagreement about the likelihood that a new investment opportunity will be available, although there may be disagreement about what it is worth. When it becomes available, the investment opportunity allows the firm to choose between a riskless "mundane project" or a risky "innovative project." This choice between the two projects will be made at $\mathrm{t}=2$, when the actual investment is made.

The mundane and innovative projects both require an investment $\mathrm{I}$ at $\mathrm{t}=2$. If no project is available and the firm has raised $\mathrm{I}$ at $\mathrm{t}=1$, then this will be worth only $\mathrm{I}[1-\delta], \delta \in(0,1)$ at $\mathrm{t}=3$, which justifies our earlier assumption that the firm will not raise external financing when it has no project available. ${ }^{11}$ The mundane project pays off a certain amount $R$ at $t=3$. We assume that the mundane project has positive NPV on an after-tax basis, i.e., R[1- $\tau]>$ I. The innovative project also pays off a random amount at $\mathrm{t}=3$, but management (insiders) and financiers (outsiders) may disagree at $\mathrm{t}=2$ about the value of this project.

We interpret the mundane and innovative projects as follows. The mundane project is a routine extension of the firm's existing business. Examples would be expanding capacity to

\footnotetext{
${ }^{10}$ The idea is that the capital appropriation request is approved at $\mathrm{t}=1$ and all the preinvestment groundwork is done between $\mathrm{t}=1$ and $\mathrm{t}=2$, which accounts for the time lag between raising funds and investing them, both here as well as in practice. Note that since the firm knows at $\mathrm{t}=1$ that it has a project before it raises funds, no efficiency is lost by raising funds prior to investment as opposed to raising funds at $t=2$.

${ }^{11}$ This "no free-disposal" assumption, combined with the assumption that $q=0$ (payoff on existing assets is normalized at zero) ensures that the firm will not benefit from raising funds at $t=1$ via debt just to exploit the debt tax shield.
} 
increase the output of an existing product, replacing old equipment with new equipment, and providing a division with investment equal to its annual depreciation to continue operations. The innovative project represents a departure from routine operations. It is thus more risky and also subject to greater potential disagreement about its value. Examples are a new business design such as e-Bay's launching of an online auction business, market entry into a new country, and acquisition of another firm such as Hewlett-Packard's acquisition of Compaq, which was the subject of considerable disagreement. It is not necessary for our analysis that the mundane project be riskless, only that it be less risky than the innovative project.

The Manager's Objective Function: The manager's objective is to maximize the expected terminal $(t=3)$ wealth of those who are shareholders at $t=0$. This means that there is no agency problem in terms of a divergence of interests between shareholders and management.

Disagreement Over Future Payoffs: Everybody agrees that the mundane project will pay off R at $t=3$. At $t=2$, management (insiders) believe that the innovative project will pay off $x+\tilde{\varepsilon}$ at $\mathrm{t}=3$, whereas investors (outsiders) believe the project will pay off $\mathrm{y}+\widetilde{\varepsilon}$ at $\mathrm{t}=3$, where $\tilde{\varepsilon}$ is a mean-zero random variable that is orthogonal to $\mathrm{x}$ as well as $\mathrm{y}$. The variance of $\tilde{\varepsilon}$ is $\sigma_{\varepsilon}^{2}<\infty$. Viewed at $\mathrm{t}=0$ and $\mathrm{t}=1, \mathrm{x}$ and $\mathrm{y}$ are random variables for all agents, with means $\mu_{\mathrm{x}}$ and $\mu_{\mathrm{y}}$ respectively. That is, $\mathrm{x}$ is the realization of a random variable that represents management's assessment at $\mathrm{t}=2$ of the expected value of the payoff on the innovative project at $\mathrm{t}=3$, and $\mathrm{y}$ is the realization of a random variable that represents investors' assessment at $\mathrm{t}=2$ of the expected value of the payoff on the innovative project at $t=3$. We assume that $x$ and $y$ are privatelyobserved valuation assessments.

At $\mathrm{t}=0$ and $\mathrm{t}=1$, the joint density $\mathrm{x}$ and $\mathrm{y}$, conditional on the correlation $\rho \in(-1,1)$ between $\mathrm{x}$ and $\mathrm{y}$, is $\mathrm{q}(\mathrm{x}, \mathrm{y} \mid \rho)$. The support of $\mathrm{q}(\cdot, \cdot \cdot)$ is $[-\infty, \infty] \times[-\infty, \infty]$. We assume that, conditional on $\rho$, the joint density $\mathrm{q}(\mathrm{x}, \mathrm{y} \mid \rho)$ is common knowledge, but it is possible for $\rho$ to be 
unknown until the firm's stock price is observed at $t=1$, and be inferred from this price in a manner that will be made precise later. The correlation coefficient $\rho$ captures the extent to which management and investors are likely to agree on the value of the innovative project. That is, $\rho$ is the "agreement parameter." The greater is $\rho$, the more likely it is that management and investors will agree on the value of the innovative project. The firm's stock price can reveal $\rho$ because investors will tend to value the firm more highly when they know that it is less likely that the firm will invest in a project that investors disapprove of. ${ }^{12}$

We assume that $\min \left\{\mu_{\mathrm{x}}, \mu_{\mathrm{y}}\right\}>\mathrm{R}$, where $\mathrm{E}(\cdot)$ is the expectation operator. If this inequality were not to hold, the innovative project would never be ex ante preferred to the mundane project and considerations of potential conflicts between insiders and outsiders would be moot in expectation. The role of this assumption will be discussed in greater detail later.

For later use, it will also be useful to note the marginal densities of $\mathrm{x}$ and $\mathrm{y}$, which are:

$$
g(x \mid \rho)=\int_{-\infty}^{\infty} q(x, y \mid \rho) d y, \text { and } h(y \mid \rho)=\int_{-\infty}^{\infty} q(x, y \mid \rho) d x
$$

Choice of financing: The firm can choose either debt or equity at $t=1$ to raise the $\$ \mathrm{I}$ it needs to finance the project. We assume that debt financing offers a tax benefit, i.e. interest payments are tax deductible, and that the tax rate is $\tau .{ }^{13}$ To simplify the analysis, we assume that the investment is either $100 \%$ debt financed or $100 \%$ equity financed. All financing is obtained at $t=1$. In the case of debt financing, the repayment obligation (at $t=3$ ) equals $D$, with $\mathrm{D}=(1+\mathrm{r}) \mathrm{I}$, where $\mathrm{r}$ is the yield on the debt.

Bondholders can veto the firm's project choice if they believe it will lower the value of the debt. Because the mundane project is riskfree and pays off $\mathrm{R}>\mathrm{I}$, bondholders will always prefer it over the innovative project, regardless of $\mathrm{y}$, as long as $\mathrm{R}$ is large enough to fully cover

\footnotetext{
${ }^{12}$ More specifically, we assume that investors collectively know $\rho$.

${ }^{13}$ Actually, to ease parametric complexity, we will assume that all payments to bondholders are tax deductible.
} 
debt repayment. Given complete veto power, debt becomes riskless (thus $\mathrm{r}=0$ ), and $\mathrm{R}$ will be large enough to fully cover debt repayment. Given this and bondholder preferences, a firm choosing debt financing will always choose the mundane project.

Things are different with equity. Shareholders will have the same preference as management if $x \geq R$ and $y \geq R$, in which case they will want to invest in the innovative project, or if $\mathrm{x}<\mathrm{R}$ and $\mathrm{y}<\mathrm{R}$, in which case they will prefer the mundane project. However, when $\mathrm{x} \geq \mathrm{R}$ and $\mathrm{y}<\mathrm{R}$, there will be a divergence of opinions as management will prefer the innovative project and the shareholders will prefer the mundane project. Because equity does not have the strict covenant structure of debt, it is a more flexible contract that gives management the ability to invest in the innovative project even if shareholders prefer the mundane project. Equity does not, however, give management unfettered flexibility. There may be instances in which shareholders will block management from pursuing a particular course of action. We assume that the degree of flexibility management has with equity depends on the corporate governance structure. Conditional on management believing that the innovative project is the optimal choice and investors believing that it is not, let $\eta \in[0,1]$ be the probability that management will be able to invest in the innovative project when the firm is all-equity financed. Hence, $1-\eta$ is the probability that shareholders can veto management's choice of the innovative project when they think that management should choose the mundane project. We will refer to $\eta$ as the "flexibility parameter". When management is blocked from investing in the innovative project, it must invest in the mundane project. Note that flexibility is an inherently asymmetric concept. It is relevant only when management wants to invest in the innovative project $(x \geq R)$ and investors don't $(y<R)$. If management does not wish to invest in the innovative project $(x<R)$, the innovative project will be eschewed regardless of what investors would like.

To recapitulate the sequence of events, at $t=0$ the firm is all-equity financed and it is 
uncertain whether a project will be available at $t=1$. At $t=1$, it becomes known whether the project is available. If the project is not available, the status-quo value of the firm is zero. Project availability means there will be a choice to be made between an innovative project and a mundane project. Management knows that at $\mathrm{t}=2$ it will receive a signal $\mathrm{x}$ and investors will receive a signal y about the expected value of the payoff of the innovative project. Viewed at $\mathrm{t}=1, \mathrm{x}$ and $\mathrm{y}$ are random variables with a joint density function $\mathrm{q}(\mathrm{x}, \mathrm{y} \mid \rho)$, where $\rho$ is the correlation coefficient between $\mathrm{x}$ and $\mathrm{y}$. Management may not know $\rho$, but the density function $q(x, y \mid \rho)$, conditional on $\rho$, is common knowledge. The firm's stock price at $t=1$ will reveal $\rho$ to management since the market will anticipate the firm's choice of security at $t=1$ and set a price conditional on all of the information available to the market at $t=1$ (including $\rho$ ). ${ }^{14}$ After observing the firm's stock price, management decides whether to raise the investment, I, needed for the project using debt or equity. No capital is raised if no project is available. At $t=2$, $x$ and $\mathrm{y}$ are observed by management and investors respectively. A choice is then made between the innovative and mundane projects. At $\mathrm{t}=3$, the payoff is observed on whatever project was chosen at $\mathrm{t}=2$ and investors are paid off. In Figure 1 we summarize the sequence of events.

\section{Figure 1 goes here}

\subsection{Discussion of the Model}

The model described thus far has two essential features that are important for the analysis that follows, as well as a noteworthy feature that matters only for how we interpret the model. First, we allow management (insiders) and investors (outsiders) to have different assessments of the value of the firm's investment opportunity, and view this as a potentially irreconcilable difference of opinions. This creates a divergence between what management wants to do and the action investors want to pursue. This divergence is neither a problem of asymmetric information

\footnotetext{
${ }^{14}$ That is, there is something the market knows that management does not. The implications of this assumption are discussed later.
} 
nor a problem of agency. That is, management and investors do not value the innovative project differently because management knows more than investors. If this were the case, as in the standard asymmetric-information setting, management could attempt to bridge the information gap through (possibly dissipative) communication. In our model, however, both management and investors see exactly the same information at $\mathrm{t}=2$; they just interpret it differently. Note also that when the firm is all-equity financed, there is no agency problem in project selection since risk-neutral management and shareholders are attempting to maximize the same objective function at $\mathrm{t}=2$ and there is no perquisites-consumption problem as in Jensen and Meckling (1976) or difference in risk-attitudes as in Ross (1973, 1979).

The second essential feature of the analysis is that equity is viewed as more flexible than debt. If equity offered no more flexibility than debt, equity would be a strictly dominated security because it lacks the tax-shield advantage of debt. Our assumptions that the mundane project is riskfree with positive NPV and bondholders can always enforce their desired project choice greatly simplify matters because they create a strict bondholder preference for the mundane project that can always be forced on the firm. Allowing the mundane project to be risky but less so than the innovative project is conceptually easy, but would algebraically complicate the analysis because bondholders may prefer the innovative project if y is sufficiently high. The more conceptually-challenging task is to endogenize the trigger mechanism for a bondholder veto as an ex-ante optimal feature of the debt contract for the firm. This, however, takes us into the realm of optimal security design, which is beyond our scope here.

Another noteworthy feature of the model is that $\rho$ is revealed to management only through the firm's stock price. Although the assumption that the market may collectively know more than management along some dimension is non-standard, it has been used before. ${ }^{15}$ The

\footnotetext{
${ }^{15}$ See Allen and Gale (1999), Boot and Thakor (1997), and Subrahmanyam and Titman (2001).
} 
justification for it is that an important role of the stock market is to aggregate diverse pieces of information and reflect these in the stock price, so that the price may reveal something no individual agent knows. It turns out that this assumption affects how we interpret the model, but not the analysis. When management is a priori unaware of $\rho$, we can interpret the security issuance decision as being made conditional on the stock price since management literally looks first at the stock price, infers $\rho$ and then figures out the optimal security to issue. If instead we were to assume that $\rho$ was known to all, it will still be the case that there will be a relationship between stock price and which security is issued at $\mathrm{t}=2$, but it will be purely coincidental in the sense that the security issuance will not be driven by the stock price but both will be driven by a common underlying factor $(\rho)$. The security issuance decision will be driven by management's knowledge of $\rho$, but there will appear to be a link between this decision and stock price because of the relationship between $\rho$ and stock price.

The key parameters in what follows are the "opportunity quality" parameter $\left(\mu_{\mathrm{x}}\right.$ or $\left.\mu_{\mathrm{y}}\right)$, the "potential agreement" parameter $(\rho)$, and the "flexibility parameter" $(\eta)$.

\section{ANALYSIS OF SECURITY ISSUANCE AND CAPITAL STRUCTURE}

The analysis proceeds in two steps. We first focus on the valuation of the firm at $t=1$ prior to the actual funding but conditional on the funding choice of the firm. This highlights the dependence of the market valuation on the degree of anticipated agreement between management and investors. We then analyze the link between the funding choice and the market valuation of the firm. This is a two-way street where the market anticipates the firm's funding choice, and the firm uses the market valuation as an input in its funding decision.

\subsection{Valuation at $t=1$ Conditional on the Firm Issuing Equity}

We first focus on the valuation of the firm's equity conditional on the firm having chosen equity financing. Recall that $\eta$ is the probability that management can go ahead with its choice of 
investment if the shareholders disagree, and $1-\eta$ is the probability that shareholders will block the firm's choice of the innovative project in case of disagreement, i.e., when $x \geq R$ and $y<R$. In that case, the mundane project will be chosen. The firm's pre-equity-issuance share price at $\mathrm{t}=1$ (anticipating equity financing) will be:

$$
\begin{aligned}
V_{y}(\rho, \eta)= & \int_{R}^{\infty} \int_{R}^{\infty}\{y[1-\tau]-I\} q(x, y \mid \rho) d x d y+\eta \int_{-\infty R}^{R} \int_{R}^{\infty}\{y[1-\tau]-I\} q(x, y \mid \rho) d x d y \\
& +[1-\eta] \int_{-\infty R}^{R} \int_{R}^{\infty}\{R[1-\tau]-I\} q(x, y \mid \rho) d x d y+\int_{-\infty-\infty}^{\infty} \int^{R}\{R[1-\tau]-I\} q(x, y \mid \rho) d x d y
\end{aligned}
$$

where the inner integral is over $x$ and the outer integral is over $y$. Note that $V_{y}(\rho, \eta)$ is the market value of the firm to those who are (initial) shareholders at $t=0$. The first term in (1) is the aftertax payoff to the initial shareholders when there is agreement that the innovative project dominates the mundane project, the second term is the payoff perceived by the shareholders when they believe the mundane project is better but management invests in the innovative project, the third term is the payoff perceived by the shareholders when they believe the mundane project is better while management believes the innovative project is better and shareholders are able to prevail, and the fourth term is the payoff when management and shareholders both agree the mundane project dominates.

Henceforth we will let the flexibility parameter $\eta$ represent the stringency of shareholder corporate governance. A lower value of $\eta$ will be taken to imply more stringent (and intrusive) corporate governance by shareholders and hence less flexibility for management.

Theorem 1: The value of the firm to the initial shareholders at $t=1, V_{y}(\rho, \eta)$, is strictly increasing in the stringency of shareholder corporate governance.

This theorem says that flexibility is a double-edged sword for management. On the one hand, greater flexibility is desirable because it increases the probability that management will be able to make a project choice at $\mathrm{t}=2$ that it believes will maximize the value of the firm at $\mathrm{t}=3$. 
On the other hand, greater flexibility (higher $\eta$ ) diminishes the firm's stock price at $t=1$ (and $\mathrm{t}=2$ ) because it increases the probability that management will be able to do something that shareholders don't want. In our analysis, we have taken the flexibility parameter $\eta$ as exogenous. However, if one were to endogenize $\eta$, the determination would depend on whose perspective (management or investors) we take in designing the ex ante efficient mechanism and the weights attached to market prices at different points in time.

For the rest of the analysis, it is convenient to assume that $\mathrm{q}(\mathrm{x}, \mathrm{y} \mid \rho)$ is bivariate normal, i.e.

$$
\mathrm{q}(\mathrm{x}, \mathrm{y} \mid \rho)=\left\{\begin{array}{l}
{\left[\frac{1}{2 \pi \sigma_{x} \sigma_{y} \sqrt{1-\rho^{2}}}\right] \times} \\
\exp \left\{-\frac{1}{2\left[1-\rho^{2}\right]}\left[\left(\frac{x-\mu_{x}}{\sigma_{x}}\right)^{2}-\frac{2 \rho\left[x-\mu_{x}\right]\left[y-\mu_{y}\right]}{\sigma_{x} \sigma_{y}}+\left(\frac{y-\mu_{y}}{\sigma_{y}}\right)^{2}\right]\right\}
\end{array}\right\}
$$

where $\sigma_{\mathrm{x}}$ and $\sigma_{\mathrm{y}}$ are the standard deviations in the marginal densities of $\mathrm{x}$ and $\mathrm{y}$ respectively. To avoid assuming that management is more or less optimistic or more or less overconfident than investors, we assume that $\mu_{\mathrm{x}}=\mu_{\mathrm{y}} \equiv \mu>0$ and $\sigma_{\mathrm{x}}=\sigma_{\mathrm{y}} \equiv \sigma<\infty$. Further,

$$
\mu>\mathrm{R}+\frac{\mathrm{I} \tau}{[1-\tau]}
$$

The parametric restriction (3), which is consistent with our earlier assumption that $\min \left\{\mu_{\mathrm{x}}, \mu_{\mathrm{y}}\right\}>\mathrm{R}$, basically says that the expected value enhancement from the innovative project, relative to the mundane project, $(\mu-\mathrm{R})(1-\tau)$, should exceed the debt tax shield provided by debt financing, I $\tau$. This condition, it turns out, is sufficient (not necessary) for equity to be the optimal security to issue over a non-empty set of exogenous parameters. We can now examine the relationship between the firm's stock price and the agreement parameter, $\rho$.

Theorem 2: Conditional on the assumption that the firm has a project available to it and that it will issue equity at $t=1$ to raise the necessary financing, the firm's pre-equity-issuance stock price is strictly increasing in the agreement parameter, $\rho$. 
This theorem is intuitive. As the potential for agreement between management and investors increases, it becomes less likely that management will invest in the innovative project when investors prefer the mundane project. Investors thus value the firm more highly when their assessment becomes more highly correlated with that of management.

There are many ways to interpret the agreement parameter, $\rho$, in this context. One is that a higher $\rho$ means that management has done a more effective job of communicating to investors the basis on which it processes information about new investment opportunities, so that investors tend to interpret a common set of information signals the same way that management does. Another is that investors have greater confidence in management's ability to identify good investment opportunities and view its communication about these opportunities as credible, so that some information that management discloses as being pertinent to assessing the innovative project is taken at "face value" by investors, rather than being independently dissected by them.

Theorem 2 says that the firm's stock price is increasing in the agreement parameter $\rho$. This suggests that even if management were a priori uninformed about $\rho$, they could invert the stock price to infer $\rho$ at $t=1$. We return to this later (Theorem 4$)$.

\subsection{The Firm's Optimal Security Issuance Decision at $t=1$}

Thus far we have focused on how investors value the firm at $t=1$. In this subsection we want to examine whether management will choose to finance with debt or equity. We thus need to value expected payoffs using management's valuation rule. The goal of management is to maximize the expected value of the payoff at $\mathrm{t}=3$ of those who are shareholders at $\mathrm{t}=0 .{ }^{16}$ That is, management seeks to maximize

\footnotetext{
${ }^{16}$ The firm's pre-security-issuance shareholder base at $\mathrm{t}=1$ is the same as that at $\mathrm{t}=0$. So, maximizing the wealth of the $\mathrm{t}=0$ shareholders is the same as maximizing the wealth of the $\mathrm{t}=1$ shareholders.
} 


$$
\begin{aligned}
V_{x}(\rho, \eta)= & \int_{R}^{\infty} \int_{R}^{\infty} x[1-\tau] q(x, y \mid \rho) d x d y+\eta \int_{-\infty R}^{R} \int_{R}^{\infty} x[1-\tau] q(x, y \mid \rho) d x d y \\
& +[1-\eta] \int_{-\infty}^{R} \int_{R}^{\infty} R[1-\tau] q(x, y \mid \rho) d x d y+\int_{-\infty}^{\infty} \int_{-\infty}^{R} R[1-\tau] q(x, y \mid \rho) d x d y-I
\end{aligned}
$$

which can be simplified and written as:

$$
\begin{aligned}
\mathrm{V}_{\mathrm{x}}(\rho, \eta)= & \int_{\mathrm{R}}^{\infty} \int_{\mathrm{R}}^{\infty} \mathrm{x}[1-\tau] \mathrm{q}(\mathrm{x}, \mathrm{y} \mid \rho) \mathrm{dxdy}+\int_{-\infty}^{\mathrm{R}} \mathrm{R}[1-\tau] \mathrm{h}(\mathrm{y} \mid \rho) \mathrm{dy}+\int_{\mathrm{R}}^{\infty} \int_{-\infty}^{\mathrm{R}} \mathrm{R}[1-\tau] \mathrm{q}(\mathrm{x}, \mathrm{y} \mid \rho) \mathrm{dxdy} \\
& +\eta \int_{-\infty \mathrm{R}}^{\mathrm{R}} \int^{\infty}[\mathrm{x}-\mathrm{R}][1-\tau] \mathrm{q}(\mathrm{x}, \mathrm{y} \mid \rho) \mathrm{dx} \mathrm{dy}-\mathrm{I}
\end{aligned}
$$

Lemma 1: $\left.\partial \mathrm{V}_{\mathrm{x}}(\rho, \eta) / \partial \rho>0\right)$

Lemma 2: Conditional on the assumption that the firm has a project available and that it issues debt at $t=1$, its pre-debt-issuance stock price will be $[R-I][1-\tau]$.

Lemma 1 is merely Theorem 2 restated for management's valuation. The intuition for Lemma 2 is straightforward. If the firm issues debt at $t=1$, it can anticipate that it will be forced to invest in the mundane project at $\mathrm{t}=2$. The reason is that the mundane project is riskless and its payoff at $t=3$ is $R>I$. Thus, bondholders expect to be repaid in full with the mundane project. Regardless of the signal y received by the bondholders about the value of the innovative project, they realize that the terminal payoff on the innovative project will be $y+\widetilde{\varepsilon}$, where $\widetilde{\varepsilon}$ is a mean-zero random variable, which means their repayment becomes subject to risk. So the bondholders always veto the innovative project at $\mathrm{t}=1$. Knowing this, the pre-debt-issuance stock price at $t=1$, set in anticipation of the debt issue and the choice of the mundane project, will be the NPV of the mundane project to the shareholders, $[R-I][1-\tau]$. Next we examine the firm's security issuance preference.

Theorem 3: Suppose the firm has a project available at $t=1$. Then there exists a critical value of the flexibility parameter, $\eta^{*}$, such that management prefers to issue equity regardless of the value of the agreement parameter $\rho$, as long as $\eta>\eta^{*}$. For each $\eta \leq \eta^{*}$, there exists a critical 
value of the agreement parameter, $\rho^{*}(\eta) \in(0,1)$, such that the firm will find it optimal to finance the project with: (a) an equity issue if the actual agreement parameter inferred from the firm's stock price, $\rho$, exceeds $\rho^{*}$, and (b) a debt issue if $\rho$ is less than or equal to $\rho^{*}$.

The intuition is as follows. When $\eta$ is very high, the fact that investors may disagree with management over the desirability of investing in the innovative project matters little to management if equity is issued. For instance, if $\eta=1$ and the firm has issued equity, shareholder dissent becomes irrelevant to management in its quest to maximize the expected terminal wealth of the initial shareholders. ${ }^{17}$ Thus, management, knowing it can invest in the innovative project at will with equity, prefers to issue equity regardless of the agreement parameter, $\rho$. However, as $\eta$ declines, equity loses flexibility and hence its attractiveness to management declines, so that at a low enough $\eta$, the agreement parameter makes a difference to the attractiveness of equity relative to debt. Holding $\eta$ fixed at some value in this range, the attractiveness of equity declines as $\rho$ declines because the lower the $\rho$ the less likely it is that management will be able to invest in the innovative project when it believes that project dominates the mundane project $(x \geq R)$. That is, the probability the mundane project will be taken increases as $\rho$ declines. And if the firm anticipates investing in the mundane project anyway, it knows that the bondholders will not veto that project, so the firm might as well take advantage of the debt tax shield by issuing debt. Thus, debt is preferred to equity for lower values of the agreement parameter $\rho$ because the flexibility distinction between debt and equity is small but debt has a tax-shield advantage. At higher values of $\rho$, equity is preferred because the flexibility advantage it offers overwhelms the tax advantage of debt. Moreover, regardless of $\rho$, debt will be preferred if the firm has no access to the innovative project or if the probability of such access is sufficiently low.

\footnotetext{
${ }^{17}$ This would not be a matter of irrelevance to management if it cared about the firm's interim stock price at $\mathrm{t}=1$ or $\mathrm{t}=2$. In the recent corporate scandals, management may have been excessively concerned with interim valuations. In our analysis, such a concern would lead to distorted security-issuance decisions.
} 
Theorem 4: Assume that the flexibility parameter $\eta<\eta^{*}$. Then it is a Nash equilibrium for the firm to issue equity when its pre-issuance stock price is relatively high, and to issue debt when its pre-issuance stock price is relatively low. When the equilibrium involves the firm issuing equity, management will be able to infer the agreement parameter $\rho$ unambiguously from the preissuance stock price. When the equilibrium involves the firm issuing debt, management will only be able to infer the range in which $\rho$ lies.

This theorem is an almost immediate consequence of combining Theorems 2 and 3 . Theorem 2 says that if we assume that the firm will issue equity, then its pre-issuance stock price is increasing in the agreement parameter $\rho$, and Theorem 3 states that the firm prefers equity financing if $\rho$ is high enough. For relatively high values of $\rho$, the firm will prefer equity, the market will correctly anticipate it and the stock price will be high (revealing a high $\rho$ ), leading the firm to issue equity, thereby confirming the market's conjecture. For relatively low values of $\rho$, the firm prefers debt, the market correctly anticipates it and sets the pre-issuance stock price assuming that the mundane project will be chosen with probability one. In a Nash equilibrium, the firm's actual security issuance decision should mirror the market's conjecture. However, since the agreement parameter is irrelevant conditional on the mundane project being chosen, the pre-issuance stock price is invariant to $\rho$ when debt is (correctly) anticipated to be issued. In this case, management can only infer that $\rho$ is below a cutoff, and not its precise value. Figure 2 shows the relationship of stock price and security issuance to the agreement parameter $\rho$.

\section{Figure 2 goes here}

This result provides a theoretical explanation for the Baker and Wurgler (2002) empirical finding that firms tend to issue equity when stock prices are high. Note, however, that unlike their conjecture that this may be due to managers thinking that investors are irrational and hence issuing equity when the perceived cost of capital is low, in our analysis this result arises from 
management's inference that investors are more likely to agree with their future decisions when stock prices are high. Everybody is acting rationally. Equity is preferred when stock prices are high because it offers management the most flexibility when stock prices are high.

Corollary 1: The critical agreement parameter, $\rho^{*}$, such that equity is preferred whenever $\rho>\rho^{*}$ and debt whenever $\rho \leq \rho^{*}$, decreases as the flexibility parameter $\eta$ increases. That is, $d \rho * d \eta<0$.

As the flexibility parameter increases, equity becomes more attractive to management because of an increase in the probability that the firm can invest in the innovative project even when investors object. Moreover, an increase in $\eta$ makes investor agreement less important to management when equity is issued. Thus, as $\eta$ increases, management prefers to issue equity for lower values of the agreement parameter.

This corollary has an interesting implication. As one increases the stringency and intrusiveness of corporate governance and investors intervene more directly in major decisions by management, $\eta$ will decrease, leading to a higher $\rho^{*}$ and a preference for debt over a larger set of agreement parameter values. Thus, debt-equity ratios are predicted to be higher in capital markets in which equity-linked corporate governance is more stringent.

Corollary 2: An increase in management's uncertainty about the innovative project $\left(\sigma_{x}^{2}\right)$ increases the regions in which management prefers to issue equity. That is, $d \eta^{*} / d \sigma_{x}<0$ and $d \rho * / d \sigma_{x}<0$

The intuition is that an increase in uncertainty enhances the value of the option that management has to invest in the innovative project. Since investing in the innovative project is only possible with equity financing, the attractiveness of equity also increases as $\sigma_{\mathrm{x}}^{2}$ increases. That is, uncertainty increases the value of the flexibility that is provided by equity.

Corollary 3: For values of the agreement parameter $\rho$ such that equity issuance is optimal at $t=1$, the pre-equity-issuance stock price is increasing in $\mu$, the expected value of the innovative 
project.

This corollary follows immediately from the observation that an increase in $\mu$ makes it more likely that the innovative project will be chosen, and, conditional on that choice, the value of the firm is higher as $\mu$ increases.

\subsection{Valuation at $t=0$ and Additional Results}

At $\mathrm{t}=0$, there is uncertainty about whether a project will be available at $\mathrm{t}=1$. The stock price of the firm at $\mathrm{t}=0$ will be:

$$
\begin{aligned}
\mathrm{V}_{\mathrm{y}}^{0}(\rho, \eta, \theta)= & \theta\left\{\mathrm{V}_{\mathrm{y}}(\rho, \eta) \mathrm{I}_{\left(\rho^{*}(\eta), 1\right]}(\rho)+[\mathrm{R}-\mathrm{I}][1-\tau] \mathrm{I}_{\left[-1, \rho^{*}(\eta)\right]}(\rho)\right\} \mathrm{I}_{\left[0, \eta^{*}\right]}(\eta) \\
& +\theta \mathrm{V}_{\mathrm{y}}(\rho, \eta) \mathrm{I}_{\left[\eta^{*}, 1\right]}(\eta)
\end{aligned}
$$

where $I_{A}(a)$ is an indicator function over the set $A$ with $I_{A}(a)=1$ if $a \in A$ and $I_{A}(a)=0$ if $a \notin A$. Thus, at $\mathrm{t}=0$, if the flexibility parameter $\eta$ is below the cutoff $\eta^{*}$ (see Theorem 3 ), the firm's security-issuance decision will depend on the agreement parameter, $\rho$. If $\rho$ falls below the cutoff $\rho^{*}(\eta)$, the firm will issue debt and the pre-issuance stock price at $t=0$ will be $[R-I][1-\tau]$. If the agreement parameter exceeds $\rho^{*}(\eta)$, the firm will issue equity and be worth $V_{y}(\rho, \eta)$. If the flexibility parameter exceeds $\eta^{*}$, the firm issues equity regardless of $\rho$ and the pre-issuance stock price is $\mathrm{V}_{\mathrm{y}}(\rho, \eta)$. In each case, the value is multiplied with $\theta$, the probability that the project will be available at $t=1$. If the project is unavailable, the firm's value is just the value of its statusquo operations, which we have normalized to zero. This leads to:

Theorem 5: Suppose we hold fixed a commonly-known stringency of corporate governance such that firms may issue either debt or equity, i.e., $\eta<\eta^{*}$. Then there exists a cutoff stock price level at $t=0$, say $\hat{V}_{y}^{0}$, such that the probability of equity issuance at $t=1$, as assessed by an econometrician who is a priori unaware of the agreement parameter $\rho$, is strictly increasing in the level of the stock price at $t=0$ for all stock prices exceeding $\hat{V}_{y}^{0}$. 
The intuition for this theorem, which refers to situations in which $\eta<\eta^{*}$, can be seen by examining (5). A higher probability of project availability $(\theta)$ increases the stock price at $t=0$, $\mathrm{V}_{\mathrm{y}}^{0}(\rho, \eta, \theta)$, since this price is increasing in $\theta .{ }^{18}$ Further, the higher is the agreement parameter $\rho$, the higher will be $V_{y}(\rho, \eta)$, whereas the value of the firm with debt financing, $[R-I][1-\tau]$, is invariant to $\rho$. Thus, for $\rho<\rho^{*}(\eta)$, increases in $\rho$ have no impact on the stock price because the firm is financing with debt, but increases in $\theta$ cause the stock price at $t=0$ to increase. In that case, stock price increases at $t=0$ do not affect the probability of an equity issue at $t=1$. For $\rho$ exceeding $\rho^{*}(\eta)$, the stock price at $\mathrm{t}=0$ is increasing in both $\rho$ and $\theta$, and, conditional on a project being available, the probability of an equity issue is one. As the probability of a project's availability rises, so does the unconditional probability of an equity issue. Hence, the probability of an equity issue at $t=1$ is nondecreasing in the stock price at $t=0$. This theorem produces the prediction that not only will equity be issued when stock prices are high, but equity issuances will be preceded by periods of high (and increasing) stock prices. This result obtains even though management is not attempting to "time" the market and issue equity at inflated prices.

This result has an immediate implication for the link between growth opportunities and security issuance. In what follows, we will refer to $\theta$ as the "likelihood of future growth opportunities" and the opportunity quality $\mu$ as the value of future growth opportunities.

Corollary 4: Suppose we hold fixed a commonly known stringency of corporate governance such that firms may choose either debt or equity (i.e., $\left.\eta<\eta^{*}\right)$, and there is a distribution of firms with agreement parameters $\rho \in(-1,1)$. Then the number of firms seeking equity financing is increasing in the likelihood $(\theta)$ and value $(\mu)$ of future growth opportunities.

The intuition is very similar to that for the previous result. An increase in $\theta$ increases the

\footnotetext{
${ }^{18}$ This would be true regardless of whether the status-quo operations had a value normalized to zero or a positive number.
} 
likelihood that the firm will seek external financing. An increase in $\mu$ means that the innovative project becomes more valuable relative to the mundane project. For any $\rho$, equity thus becomes more attractive relative to debt. Thus, the cutoff $\rho^{*}$ above which $\rho$ must lie for the firm to prefer equity declines as $\mu$ increases, and more firms opt for equity.

\subsection{What Determines The Degree of Flexibility?}

We have used $\eta$ to represent the exogenous degree of flexibility that management has with equity. It is useful now to discuss what might affect $\eta$.

We have argued that $\eta$ depends on the stringency of corporate governance, which in turn is likely to depend on the performance of the firm in previous periods. We can think of $\eta$ being revised based on how investors "grade" management's performance. When the firm performs well, perhaps after having made some decisions that investors may have disagreed with, the board of directors is likely to "cut management some more slack", even if doing so causes the stock price to suffer in the short run, i.e., we should expect $\eta$ to be non-decreasing in the firm's past performance. Examples of this can be found in the degrees of latitude enjoyed by successful CEOs like Jack Welch (GE), Michael Eisner (Walt Disney) and Roberto Gouizetta (Coca-Cola), relative to the many CEOs who were increasingly restricted in their strategic choices by the boards of firms that were performing poorly. This means that firms that have consistently done well—with performance being measured on the basis of accounting earnings and/or shareholder returns - can be expected to enjoy higher flexibility with equity and find equity relatively more attractive. They will consequently rely more on equity and develop lower leverage ratios than firms that have not performed as well.

Another factor that may affect $\eta$ is the distribution of shareholder ownership. When ownership is relatively concentrated, we would expect $\eta$ to be low. The reason is that 
shareholders who own large blocks of shares should find it relatively easy to block management from making investments that shareholders do not believe are prudent for the firm. This will be more difficult to do when ownership is more diffuse.

To recapitulate, the agreement parameter $\rho$ is likely to be affected by the effectiveness of management's communication of the firm's future prospects. The more effective this communication, the more highly correlated investors' opinions are likely to be with those of management. The flexibility parameter $\eta$ is likely to be affected by the firm's performance. The better the firm's past performance, the higher we should expect $\eta$ to be.

\subsection{Security Issuance Announcement Effects}

In our model, the revelation that a project is available and the raising of the capital for the project occur simultaneously at $\mathrm{t}=1$. This means there will be an announcement effect at $\mathrm{t}=1$ that will reflect both the resolution of uncertainty about project availability and whether investors agree with the firm's choices of project and funding source. The announcement effect will thus be stronger for "longer-shot" projects, those with lower probabilities of project availability. The announcement effect of a debt-financed project will generally be small. ${ }^{19}$ The reason is that debt financing always leads to the choice of the mundane project, which has a modest NPV, and there is no disagreement about this project's value.

The announcement effect of equity depends on the agreement parameter $\rho$ and the flexibility parameter $\eta$. When $\rho$ is high, disagreement is unlikely and the equity-announcement effect is positive on average regardless of $\eta$. But this announcement effect is decreasing in $\eta$. That is, for high $\rho$ and low $\eta$, the probability of disagreement is low and the likelihood that the manager will go against the investors if there is disagreement is also low, so the announcement

\footnotetext{
${ }^{19}$ This announcement effect should be typically positive. However, if investors assign a high probability ex ante that a project will be available at $\mathrm{t}=1$ and the perceived likelihood of disagreement is low, then the prior on the innovative project will be high. The choice of debt financing and the mundane project will then be viewed as "bad news", generating a negative announcement effect.
} 
effect is the highest for this combination. For low $\rho$, disagreement is quite likely, and the sign of the announcement effect depends critically on $\eta$. When $\eta$ is sufficiently high, disagreement is virtually irrelevant for management in terms of its ability to invest in the innovative project. In that case, the equity-announcement effect will be negative on average for sufficiently low $\rho$, since investors are very likely to face an investment they do not like. If both $\rho$ and $\eta$ are low, debt dominates and no equity issuance should be observed. But if equity is issued anyway, the announcement effect will be the most negative.

These results have important cross-sectional implications. The low- $\eta$-and-high- $\rho$ case is descriptive of firms with more concentrated ownership (in the extreme, privately-held firms). These firms would experience the most positive equity-issuance announcement effects. Publicly-held firms with more diffuse ownership will typically give management more say in running the firm (higher $\eta$ ). Announcement effects will be smaller for such firms, becoming negative at sufficiently low value of $\rho$. Thus, if we examine the cross-section of firms, we would expect more negative equity issuance announcement effects among firms with more diffuse ownership and more positive equity issuance announcement effects among firms with more concentrated ownership (low $\eta$ and high $\rho$ ). ${ }^{20}$

Our analysis also suggests a link between the equity issuance announcement effect and long-term performance. In cases where $\eta$ is high but $\rho$ is low, the announcement effect of an equity issue (combined with investment in the innovative project) will be negative, but long-run performance will be positive if management was right.

\subsection{Implications for the Capital Structure of the Firm}

Thus far we have considered a setting in which the firm starts out with an all-equity

\footnotetext{
${ }^{20}$ Since the choice between public and private ownership is endogenous in practice, one would have to be careful in the empirical design.
} 
capital structure and then examined the changes in this capital structure due to subsequent security issuances. But what about a firm that already has debt in its capital structure?

The presence of pre-existing debt affects management's total flexibility in any period, and this will affect its security issuance decision in that period. Consider now such a firm that finds itself in period t with a new project, an associated security-issuance decision, and an inherited leverage ratio (book value of debt/sum of the book value of debt and the market value of equity) of $\mathrm{L}_{\mathrm{t}}$ that defines a particular degree of flexibility for management. Suppose now that the firm's stock price is relatively high in the sense that the value of flexibility exceeds the value of the debt tax shield. Then, as our analysis has shown, management will issue equity to finance the new project. Consequently, its leverage ratio will be driven down further. By contrast, if the firm's stock price is relatively low, its leverage ratio will (by definition) be high. Moreover, management will perceive the flexibility provided by equity to be correspondingly low, and will thus prefer to issue debt, further driving up the leverage ratio.

This has a rather dramatic implication for the current capital structure debate. The standard "tradeoff theories" of capital structure have asserted a (static) target debt-equity ratio that firms strive to maintain. ${ }^{21}$ The recent empirical evidence (see Baker and Wurgler (2002), Hovakimian, Opler and Titman (2001), and Welch (2002) for U.S. firms, and Antoniou, Guney and Paudyal (2002) for French, British and German firms) indicates that:

(1) Capital structure appears to be driven by stock price/stock returns more than other factors.

(2) Rather than issuing debt when their stock price is high (so as to return to a target leverage ratio), firms tend to issue equity.

Based on this, these papers have concluded that firms do not appear to have target capital structures as suggested by the tradeoff theories of capital structure. What our analysis shows is

\footnotetext{
${ }^{21}$ The term "tradeoff theories" was used by Baker and Wurgler (2002).
} 
that the fact that capital structure is driven by stock price levels is not inconsistent with the notion of a target leverage ratio. However, there is no such thing as a static target leverage ratio; it is a function of the firm's stock price and hence inherently dynamic.

A key empirical implication of this is that capital structure, rather than adjusting back to some static target, will appear to move further away from this target as it responds to stock price movements. When the firm's stock price increases, it produces two effects: a mechanistic decline in its leverage ratio and an enhanced flexibility-driven desire to issue equity. The second effect reinforces the first. Similarly, when the firm's stock price decreases, it also produces two reinforcing effects: a mechanistic increase in its leverage ratio and an enhanced desire to issue debt. That is, movements in stock prices engender two effects on capital structure, a mechanistic effect and possibly a reactive (to the stock price) capital structure adjustment effect, with both effects working in concert rather than against each other as suggested by existing theories.

All this assumes that the firm has a new project. If such a project is not available, there may not be any security issuances (reactive capital structure adjustments), so that capital structure is driven only mechanistically by stock price changes. Alternatively, if the stock price rises sufficiently, the firm may issue new equity to retire existing debt, rather than avoiding new capital due to lack of project availability. And if the stock price drops sufficiently, it may issue new debt to repurchase stock. In either case, if there is a reactive capital structure adjustment, it will reinforce the mechanistic effect of the stock price movement on capital structure.

Our discussion has focused on the flexibility tradeoff between debt and equity. In practice, there are also other ways for management to acquire flexibility. One such way is to accumulate excess liquidity within the firm. Such liquidity enables management to make investment decisions without the scrutiny and possible objections and restrictions that may accompany external financing. Thus, management that perceives an investment opportunity set 
that requires greater flexibility is likely to accumulate more excess liquidity via retained earnings and use less debt. The prediction then is a negative cross-sectional relationship between excess liquidity accumulation and debt-equity ratios.

\subsection{Shareholder Preferences and the Role of Debt}

Although the security-issuance decision is made by management at $\mathrm{t}=1$, we can ask what shareholders would want. Comparing (1) and (4), it is easy to show that $V_{x}(\rho, \eta)>V_{y}(\rho, \eta) \forall \rho$ and $\eta$ when $\mu_{x}=\mu_{y}$ and $\sigma_{x}=\sigma_{y}$. This means that the cutoff agreement parameter, $\rho_{y}^{*}$, at which the shareholders would like equity to be issued is higher than the corresponding cutoff $\rho^{*}$ chosen by management. This is the shaded area in Figure 2, i.e., when $\rho \in\left(\rho^{*}, \rho_{\mathrm{y}}^{*}\right)$, management wants to issue equity but shareholders would like debt to be issued. The intuition is that flexibility is valued positively by management and negatively by shareholders, so the latter value equity (with its greater flexibility) less than the former.

This means that for intermediate values of the stock price, those corresponding to $\rho \in\left(\rho^{*}, \rho_{y}^{*}\right)$, debt can serve a role even without taxes. Since a precommitment by management to issue debt in this range increases the firm's stock price at both $t=0$ and $t=1$, the Board of Directors may wish to limit management's flexibility about which security to issue at $t=1$. While this would leave our analysis qualitatively unchanged-only the range of values of $\rho$ for which equity is issued would decline to $\left(\rho_{y}^{*}, 1\right]$ - it would carve out a role for debt as a "flexibility-limiting" instrument for stock prices below a threshold. Debt can thus be useful even without taxes, agency costs or signaling considerations because it can serve as a form of "investor protection" that is distinct from the usual protection from self-serving managerial expropriation (e.g. Shleifer and Wolfenzon (2002)). That is, the tax advantage of debt is 
necessary to get management to ever use debt, but shareholders may want debt even without this advantage.

\section{EMPIRICAL IMPLICATIONS}

In this section we discuss numerous empirical implications of our analysis. While our first prediction is what the model was designed to generate and the next three predictions are supported by the existing evidence, the remaining empirical implications are new, so they may be used to differentiate our theory from others and also to potentially reject the model.

1. The firm's capital structure will be determined dynamically by the response of the manager to the information he gleans from his firm's stock price. That is, management's perception of the firm's optimal capital structure varies with the firm's stock price. Firms will issue equity when the stock price is high and debt when the stock price is relatively low.

This prediction follows from Theorem 4 and our discussion in Section 3.6. It is consistent with the empirical evidence in Baker and Wurgler (2002), Hovakimian, Opler and Titman (2001) and Welch (2002). It is also consistent with the evidence in Antoniou, Guney and Paudyal (2002), Barclay, Smith and Watts (1995) and Rajan and Zingales (1995) that the crosssectional relationship between market-to-book ratios and leverage ratios is negative for U.S. and OECD firms. However, our result arises for reasons almost completely unrelated to the conjectures offered in these empirical papers. For example, Baker and Wurgler (2002) suggest that their finding may be attributable to market timing efforts by managers who think investors are irrational and raise equity when the cost of equity is perceived to be low. Barclay, Smith and Watts (1995) and Rajan and Zingales (1995) explain their findings by arguing that growth options and hence associated agency costs of debt and bankruptcy costs are high precisely when stock prices are high, so firms would prefer to issue equity rather than debt. And Welch (2002) 
points out that a significant percentage of the observed changes in capital structure is driven by the mechanistic effect of stock returns, with the remainder accounted for by capital structure activity that "...remains a mystery." He concludes that capital structure is "inert."

By contrast, our theory predicts that capital structure is anything but inert. It varies continuously with the firm's stock price since the firm's decision of which security to issue at any point in time is driven by management's perceived tradeoff between flexibility and debt tax shields, and this tradeoff depends on the observed stock price.

2. As the likelihood and value of future growth opportunities increase, firms rely more on equity financing and their leverage ratios decline. Similarly, if the firm operates in an environment in which the probability of having innovative projects to invest in is sufficiently low, its leverage ratio will be high.

This prediction comes from Corollary 4 and the discussion following Theorem 3 . It is consistent with the evidence for the U.S. defense industry provided by Goyal, Lehn and Racic (2002). Their evidence is that the debt levels of U.S. weapons manufacturers increased as their growth opportunities declined during 1985-95. Moreover, the finding that leverage ratios will be high among firms — such as regulated utilities — that operate in industries that mostly provide opportunities to invest in mundane projects is also consistent with the evidence.

3. Firms with better prior performance in terms of profitability will have lower leverage ratios than firms with poorer prior profitability.

This prediction was discussed in Section 3.4. It is consistent with the evidence in Antoniou, Guney and Paudyal (2002). They find that the long-run relation between the profitability of a firm and its market leverage is significantly negative in France and the U.K. Rajan and Zingales (1995) founed a similar relationship for firms in the OECD countries.

4. There will be a negative cross-sectional relationship between variables that proxy for 
higher management flexibility - such as excess liquidity accumulation within the firm and debt-equity ratios.

We discussed this prediction in Section 3.6. Whenever the flexibility associated with equity is higher, we would expect management to explore all opportunities to increase flexibility. Building up liquidity reserves is one way to do this, so the theory predicts that low-debt firms will also have high cash reserves relative to their industry peers. Microsoft, which has no debt and substantial cash reserves, is only a very dramatic illustration of this prediction. This prediction is consistent with the evidence in Ozkan and Ozkan (2002) that the cross-sectional relationship between liquidity and leverage is negative for U.K. companies.

\section{An increase in uncertainty leads to lower leverage ratios.}

This prediction follows from Corollary 2. While it is also consistent with other theories of capital structure, such as agency theory and the bankruptcy-cost argument, it obtains here for different reasons. In particular, higher uncertainty lowers the critical cutoff values for both the flexibility and agreement parameters above which equity is preferred to debt.

6. Debt-equity ratios will be higher in capital markets in which equity-linked corporate governance is more active and intrusive and in firms with more independent and active boards of directors.

This prediction follows from Corollary 1. As we showed, if shareholders begin to restrict management's flexibility, the value of equity to management goes down, and the tradeoff shifts in favor of debt. We are not aware of any existing evidence on this prediction. It may be ideal to test this prediction in an international context, so that one can compare capital structure choices across capital markets distinguished by different degrees of shareholder activism. However, it may even be possible to test this within the context of a single capital market, such as the U.S. The corporate governance literature has developed empirical proxies for the intensity with which 
boards of directors monitor management, and the cross-sectional differences in intensity among U.S. firms could permit testing this prediction.

7. When the firm's stock price changes, its leverage ratio will move in the direction implied by the mechanistic effect of the price change on leverage. Moreover, this change in leverage will be at least as great as that implied by the mechanistic effect and may even exceed it.

This prediction was discussed in Section 3.6, and can be understood as follows. Suppose we have three leverage ratios: $\mathrm{L}_{1}<\mathrm{L}_{0}<\mathrm{L}_{2}$. If an increase in the stock price causes the firm's leverage ratio to mechanistically decline from $L_{0}$ to $L_{1}$, the firm may undertake a reactive capital structure adjustment that results in an eventual leverage ratio of $\mathrm{L}^{*} \leq \mathrm{L}_{1}$. Similarly, if a decrease in the stock price causes the firm's leverage ratio to mechanistically increase from $\mathrm{L}_{0}$ to $\mathrm{L}_{2}$, the firm's actual leverage ratio will be $\mathrm{L}^{*} \geq \mathrm{L}_{2}$. While this "overshooting" prediction is broadly consistent with the recent empirical evidence, we are not aware of any specific test of this prediction in the existing literature.

8. Equity issuance will be preceded by periods of relatively high stock price.

This prediction comes from Theorem 5. One implication of this prediction is that if one views firms as attempting to time the market in their equity issuance decisions, it will appear that they are inexplicably delaying their equity issues, waiting for prices to become even higher before issuing equity. Again, we are not aware of any direct test of this prediction.

9. When external financing is raised to finance a new project, equity will have the largest announcement effect, whereas debt will have a smaller announcement effect on average. The announcement effect of equity will be positive when the pre-issuance stock price is relatively high and negative when the pre-issuance stock price is relatively low. Similarly, the announcement effect of debt will be smaller (and possibly 


\section{negative) when the stock price is higher.}

These predictions were discussed in Sections 3.5 and 3.6. When the agreement parameter $\rho$ is high, the firm's stock price will be high. Thus, if the firm elects to invest in an innovative project, investors are likely to agree with this choice, so the equity announcement effect will be positive. Similar logic applies to the case in which $\rho$ is low and the pre-issuance stock price is low. In the case of a debt issue, when the stock price is high (high $\rho$ ), a debt-cum-mundaneproject announcement is a negative surprise.

\section{The equity issuance announcement effect is most pronounced for long-shot projects.}

This prediction was also discussed in Section 3.5. A long-shot innovative project has a low probability of being available, leading to a larger (more positive) equity announcement effect. That is, a firm that was a priori expected to not have a project opportunity will experience a relatively substantial equity announcement effect. The sign of the announcement effect is addressed in Prediction 9.

\section{Firms with more concentrated equity ownership structures will, on average, experience} equity-issuance announcement effects that are larger.

This prediction too was discussed in Section 3.5. More concentrated ownership typically leads to greater intervention by the financiers (low $\eta$ ) and thus gives rise to a larger equityissuance announcement effect. It would be interesting to test this prediction both crosssectionally as well as in an international context where we would expect to find significant crosssectional variation in ownership concentration.

\section{CONCLUSION}

Our goal in this paper has been to introduce the concept of flexibility as an important determinant of the security issuance decision and to understand its capital structure implications. 
Our theory correctly predicts some of the known stylized facts about capital structure that are at odds with existing capital structure theories and also generates additional testable predictions.

At the heart of our theory is the notion that people confronted with the same information may disagree on the optimal course of action, and that this leads management to value the flexibility to pursue what it believes is optimal in the face of such disagreement. Such flexibility is not valued equally at all times; its value depends on the decisions management intends to make in the future and how much disagreement these decisions are likely to spark. Equity, which is more flexible than debt, will be preferred when future decisions are likely to involve substantial risk and shareholders are sufficiently more likely (than creditors) to agree with management. Thus, flexibility considerations are likely to dictate which security the firm issues, and the tradeoff between flexibility and tax shields is dynamic. Moreover, the potential for future disagreement also affects the firm's stock price since it informs investors about the likelihood that management will do something in the future that investors don't like. This creates a natural link between the security-issuance decision and the firm's stock price via their common dependence on the value of flexibility. With this link, the notion of a static optimal capital structure is rendered obsolete. The firm has an optimal capital structure at every point in time, but it dynamically depends on its stock price. Thus, the notion of an optimal capital structure is not inconsistent with observed capital structures being driven largely by stock prices/returns.

We have taken debt and equity as given here, although we have provided a new rationale for shareholders to prefer debt even without taxes, agency costs or signaling considerations. It would be interesting to endogenize debt and equity in a mechanism design framework using flexibility as one of the determinants of security design. ${ }^{22}$

\footnotetext{
${ }^{22}$ This would provide an alternative to the risk-sharing and information-based approaches to security design currently in vogue, e.g. Allen and Gale (2000), and Fulghieri and Lukin (2001).
} 


\section{APPENDIX}

Proof of Theorem 1: Rearranging (1) we get:

$$
\begin{aligned}
\mathrm{V}_{\mathrm{y}}(\rho, \eta)= & \int_{\mathrm{R}}^{\infty} \int_{\mathrm{R}}^{\infty}\{\mathrm{y}[1-\tau]\} \mathrm{q}(\mathrm{x}, \mathrm{y} \mid \rho) \mathrm{dx} d \mathrm{y}-\mathrm{I}+\int_{-\infty-\infty}^{\mathrm{R}} \int^{\infty} \mathrm{R}[1-\tau] \mathrm{q}(\mathrm{x}, \mathrm{y} \mid \rho) \mathrm{dx} d \mathrm{y} \\
& +\int_{\mathrm{R}}^{\infty} \int_{-\infty}^{\mathrm{R}} \mathrm{R}[1-\tau] \mathrm{q}(\mathrm{x}, \mathrm{y} \mid \rho) \mathrm{dxdy}-\eta \int_{-\infty}^{\mathrm{R}} \int^{\infty}[\mathrm{R}-\mathrm{y}][1-\tau] \mathrm{q}(\mathrm{x}, \mathrm{y} \mid \rho) \mathrm{dx} d \mathrm{y}
\end{aligned}
$$

It is clear that $\partial \mathrm{V}_{\mathrm{y}}(\rho, \eta) / \partial \eta<0$.

Proof of Theorem 2: We know that the firm's pre-equity-issuance stock price at $\mathrm{t}=1$ can be expressed as in (A-1). Now define

$$
\mathrm{u} \equiv \frac{\mathrm{x}-\mu_{\mathrm{x}}}{\sigma_{\mathrm{x}}}, \quad \mathrm{w} \equiv \frac{\mathrm{y}-\mu_{\mathrm{y}}}{\sigma_{\mathrm{y}}}
$$

Substituting (A-2) in (A-1) and writing $\mathrm{q}(\mathrm{x}, \mathrm{y} \mid \rho)$ as a bivariate normal density using (2), we can express (A-1) as:

$$
\begin{aligned}
\mathrm{V}_{\mathrm{y}}(\rho, \eta)= & \int_{\left[\mathrm{R}-\mu_{\mathrm{y}}\right] / \sigma_{\mathrm{y}}}^{\infty} \int_{\left[\mathrm{R}-\mu_{\mathrm{x}}\right] / \sigma_{\mathrm{x}}}^{\infty}\left\{\left[w \sigma_{\mathrm{y}}+\mu_{\mathrm{y}}\right][1-\tau]\right\} \hat{\mathrm{q}}(\mathrm{u}, \mathrm{w}) \mathrm{dudw} \\
& +\int_{-\infty}^{\left[\mathrm{R}-\mu_{\mathrm{y}}\right] / \sigma_{\mathrm{y}}} \int_{-\infty}^{\infty} \mathrm{R}[1-\tau] \hat{\mathrm{q}}(\mathrm{u}, \mathrm{w}) \mathrm{dudw}+\int_{\left[\mathrm{R}-\mu_{\mathrm{y}}\right] / \sigma_{\mathrm{y}}}^{\infty} \int_{-\infty}^{\left[\mathrm{R}-\mu_{\mathrm{x}}\right] / \sigma_{\mathrm{x}}} \mathrm{R}[1-\tau] \hat{\mathrm{q}}(\mathrm{u}, \mathrm{w}) \mathrm{dudw} \\
& -\eta \int_{-\infty}^{\left[\mathrm{R}-\mu_{\mathrm{y}}\right] / \sigma_{\mathrm{y}}} \int_{\left[\mathrm{R}-\mu_{\mathrm{x}}\right] / \sigma_{\mathrm{x}}}^{\infty}\left[\mathrm{R}-\mathrm{w} \sigma_{\mathrm{y}}-\mu_{\mathrm{y}}\right][1-\tau] \hat{\mathrm{q}}(\mathrm{u}, \mathrm{w}) \mathrm{dudw}-\mathrm{I}
\end{aligned}
$$

where $\hat{\mathrm{q}}(\mathrm{u}, \mathrm{w}) \equiv \frac{\exp \left\{-\left[(1 / 2) /\left(1-\rho^{2}\right)\right]\left[\mathrm{u}^{2}-2 \rho \mathrm{uw}+\mathrm{w}^{2}\right]\right\}}{2 \pi \sqrt{1-\rho^{2}}}$, which upon simplification yields:

$$
\hat{\mathrm{q}}(\mathrm{u}, \mathrm{w}) \equiv \frac{\exp \left\{-\left[(1 / 2) /\left(1-\rho^{2}\right)\right]\left[(\mathrm{u}-\rho \mathrm{w})^{2}+\left(1-\rho^{2}\right) \mathrm{w}^{2}\right]\right\}}{2 \pi \sqrt{1-\rho^{2}}}
$$


Now substitute $\alpha \equiv \frac{\mathrm{u}-\rho \mathrm{w}}{\sqrt{1-\rho^{2}}}$ and $\mathrm{d} \alpha=\frac{\mathrm{du}}{\sqrt{1-\rho^{2}}}$ into (A-3), use the fact that $\mu_{\mathrm{x}}=\mu_{\mathrm{y}}=\mu$, $\sigma_{\mathrm{x}}=\sigma_{\mathrm{y}}=\sigma$, and rearrange to write:

$$
\begin{aligned}
\mathrm{V}_{\mathrm{y}}(\rho, \eta)= & \int_{[\mathrm{R}-\mu] / \sigma}^{\infty}\left\{\int_{\mathrm{J}(\rho, \mathrm{w})}^{\infty} \frac{\mathrm{e}^{-\alpha^{2} / 2}}{\sqrt{2 \pi}} \mathrm{d} \alpha\right\} \frac{[\mathrm{w} \sigma+\mu][1-\tau] \mathrm{e}^{-\mathrm{w}^{2} / 2}}{\sqrt{2 \pi}} \mathrm{dw} \\
& +\eta \int_{-\infty}^{[\mathrm{R}-\mu] / \sigma}\left\{\int_{\mathrm{J}(\rho, \mathrm{w})}^{\infty} \frac{\mathrm{e}^{-\alpha^{2} / 2}}{\sqrt{2 \pi}} \mathrm{d} \alpha\right\} \frac{[\mathrm{w} \sigma+\mu][1-\tau] \mathrm{e}^{-\mathrm{w}^{2} / 2}}{\sqrt{2 \pi}} \mathrm{dw} \\
& +\int_{-\infty}^{[\mathrm{R}-\mu] / \sigma} \frac{\mathrm{R}[1-\tau] \mathrm{e}^{-\mathrm{w}^{2} / 2}}{\sqrt{2 \pi}} \mathrm{dw}-\int_{[\mathrm{R}-\mu] / \sigma}^{\infty}\left[\int_{-\infty}^{\mathrm{J}(\rho, \mathrm{w})} \frac{\mathrm{e}^{-\alpha^{2} / 2}}{\sqrt{2 \pi}} \mathrm{d} \alpha\right] \frac{\mathrm{R}[1-\tau] \mathrm{e}^{-\mathrm{w}^{2} / 2}}{\sqrt{2 \pi}} \mathrm{dw} \\
& -\eta \int_{-\infty}^{[\mathrm{R}-\mu] / \sigma}\left\{\int_{\mathrm{J}(\rho, \mathrm{w})}^{\infty} \frac{\mathrm{e}^{-\alpha^{2} / 2}}{\sqrt{2 \pi}} \mathrm{d} \alpha\right\} \frac{\mathrm{R}[1-\tau] \mathrm{e}^{-\mathrm{w}^{2} / 2}}{\sqrt{2 \pi}} \mathrm{dw}
\end{aligned}
$$

where $J(\rho, w) \equiv \frac{\{[R-\mu] / \sigma\}-\rho w}{\sqrt{1-\rho^{2}}}$

Also define $P(J(\rho, w)) \equiv \int_{J(\rho, w)}^{\infty} \frac{e^{-\alpha^{2} / 2}}{\sqrt{2 \pi}} d \alpha$

Adding and subtracting equal quantities and rearranging, we obtain

$$
\begin{aligned}
\mathrm{V}_{\mathrm{y}}(\rho, \eta)= & \int_{[\mathrm{R}-\mu] / \sigma}^{\infty} \frac{\mathrm{P}(\mathrm{J}(\rho, \mathrm{w}))[\mathrm{w} \sigma+\mu][1-\tau] \mathrm{e}^{-\mathrm{w}^{2} / 2}}{\sqrt{2 \pi}} \mathrm{dw}+\int_{-\infty}^{[\mathrm{R}-\mu] / \sigma} \frac{\mathrm{P}(\mathrm{J}(\rho, w))[w \sigma+\mu][1-\tau] \mathrm{e}^{-\mathrm{w}^{2} / 2}}{\sqrt{2 \pi}} \mathrm{dw} \\
& -[1-\eta] \int_{-\infty}^{[\mathrm{R}-\mu] / \sigma} \frac{\mathrm{P}(\mathrm{J}(\rho, \mathrm{w}))[\mathrm{w} \sigma+\mu][1-\tau] \mathrm{e}^{-\mathrm{w}^{2} / 2}}{\sqrt{2 \pi}} \mathrm{dw}+\int_{-\infty}^{[\mathrm{R}-\mu] / \sigma} \frac{\mathrm{R}[1-\tau] \mathrm{e}^{-\mathrm{w}^{2} / 2}}{\sqrt{2 \pi}} \mathrm{dw}-\mathrm{I} \\
& +\int_{[\mathrm{R}-\mu] / \sigma}^{\infty} \frac{[1-\mathrm{P}(\mathrm{J}(\rho, w))] \mathrm{R}[1-\tau] \mathrm{e}^{-\mathrm{w}^{2} / 2}}{\sqrt{2 \pi}} \mathrm{dw}-\eta \int_{-\infty}^{[\mathrm{R}-\mu] / \sigma} \frac{\mathrm{P}(\mathrm{J}(\rho, \mathrm{w})) \mathrm{R}[1-\tau] \mathrm{e}^{-\mathrm{w}^{2} / 2}}{\sqrt{2 \pi}} \mathrm{dw}
\end{aligned}
$$

which can then be simplified by combining terms: 


$$
\begin{aligned}
\mathrm{V}_{\mathrm{y}}(\rho, \eta)= & \int_{-\infty}^{\infty} \frac{\mathrm{P}(\mathrm{J}(\rho, \mathrm{w}))[\mathrm{w} \sigma+\mu][1-\tau] \mathrm{e}^{-\mathrm{w}^{2} / 2}}{\sqrt{2 \pi}} \mathrm{dw} \\
& +\int_{-\infty}^{[\mathrm{R}-\mu] / \sigma} \frac{\mathrm{R}[1-\tau] \mathrm{e}^{-\mathrm{w}^{2} / 2}}{\sqrt{2 \pi}} \mathrm{dw}+\int_{[\mathrm{R}-\mu] / \sigma}^{\infty} \frac{[1-\mathrm{P}(\mathrm{J}(\rho, w))] \mathrm{R}[1-\tau] \mathrm{e}^{-\mathrm{w}^{2} / 2}}{\sqrt{2 \pi}} \mathrm{dw} \\
& -\int_{-\infty}^{[\mathrm{R}-\mu] / \sigma} \frac{\mathrm{P}(\mathrm{J}(\rho, w))\{\eta \mathrm{R}+[1-\eta][w \sigma+\mu]\}[1-\tau] \mathrm{e}^{-\mathrm{w}^{2} / 2}}{\sqrt{2 \pi}} \mathrm{dw}-\mathrm{I}
\end{aligned}
$$

Our goal is to show that $\partial \mathrm{V}_{\mathrm{y}}(\rho, \eta) / \partial \rho>0$.

To show this, we begin by noting that

$$
\mathrm{dP}(\mathrm{J}(\rho, w)) / \mathrm{d} \rho=[\partial \mathrm{P} / \partial \mathrm{J}][\partial \mathrm{J} / \partial \rho]
$$

where $\partial \mathrm{P} / \partial \mathrm{J}<0$ always and

$$
\partial \mathrm{J} / \partial \rho=\frac{\{\rho[\mathrm{R}-\mu] / \sigma\}-\mathrm{w}}{\left[1-\rho^{2}\right]^{3 / 2}}
$$

Now differentiating (A-5) with respect to $\rho$ yields

$$
\begin{aligned}
\partial \mathrm{V}_{\mathrm{y}}(\rho, \eta) / \partial \rho= & \int_{-\infty}^{\infty} \frac{[\mathrm{dP} / \mathrm{d} \rho][\mathrm{w} \sigma+\mu][1-\tau] \mathrm{e}^{-\mathrm{w}^{2} / 2}}{\sqrt{2 \pi}} \mathrm{dw} \\
& -\int_{[\mathrm{R}-\mu] / \sigma}^{\infty} \frac{[\mathrm{dP} / \mathrm{d} \rho] \mathrm{R}[1-\tau] \mathrm{e}^{-\mathrm{w}^{2} / 2}}{\sqrt{2 \pi}} \mathrm{dw} \\
& -\int_{-\infty}^{[\mathrm{R}-\mu \mathrm{l} / \sigma} \frac{[\mathrm{dP} / \mathrm{d} \rho][\eta \mathrm{R}+[1-\eta][\mathrm{w} \sigma+\mu]\}[1-\tau] \mathrm{e}^{-\mathrm{w}^{2} / 2}}{\sqrt{2 \pi}} \mathrm{dw} \\
& =\int_{[\mathrm{R}-\mu] / \sigma}^{\infty} \frac{[\mathrm{dP} / \mathrm{d} \rho][\mathrm{w} \sigma+\mu-\mathrm{R}][1-\tau] \mathrm{e}^{-\mathrm{w}^{2} / 2}}{\sqrt{2 \pi}} \mathrm{dw} \\
& +\int_{-\infty}^{[\mathrm{R}-\mu] / \sigma} \frac{[\mathrm{dP} / \mathrm{d} \rho][\mathrm{w} \sigma+\mu-\mathrm{R}] \eta[1-\tau] \mathrm{e}^{-\mathrm{w}^{2} / 2}}{\sqrt{2 \pi}} \mathrm{dw}
\end{aligned}
$$

It is clear that the second term in (A-8) is positive. To see this, note that for $\mathrm{w} \in(-\infty,[\mathrm{R}-\mu] / \sigma)$, we have $w \sigma+\mu<\mathrm{R}$, so $w \sigma+\mu-\mathrm{R}<0$. Further, 


$$
\begin{aligned}
\mathrm{dP} / \mathrm{d} \rho & =\frac{-\mathrm{e}^{-\mathrm{J}^{2} / 2}[\{\rho[\mathrm{R}-\mu] / \sigma\}-\mathrm{w}]}{\sqrt{2 \pi}\left[1-\rho^{2}\right]^{3 / 2}} \\
& <0 \forall \mathrm{w} \in(-\infty,[\mathrm{R}-\mu] / \sigma)
\end{aligned}
$$

We will now show that the first term is strictly positive as well. Substituting for $\mathrm{dP} / \mathrm{d} \rho$, we can write it as:

$$
\begin{aligned}
& \int_{[\mathrm{R}-\mu] / \sigma}^{\infty} \frac{-\mathrm{e}^{-\mathrm{J}^{2} / 2}[\{\rho[\mathrm{R}-\mu] / \sigma\}-\mathrm{w}][\mathrm{w} \sigma+\mu-\mathrm{R}][1-\tau] \mathrm{e}^{-\mathrm{w}^{2} / 2}}{2 \pi\left[1-\rho^{2}\right]^{3 / 2}} \mathrm{dw} \\
& =\int_{[\mathrm{R}-\mu] / \sigma}^{[\mu-\mathrm{R}] / \sigma}\left\{\frac{\mathrm{e}^{-\mathrm{J}^{2} / 2}\left[\mathrm{w}+\frac{[\mu-\mathrm{R}]}{\sigma} \rho\right][\mathrm{w} \sigma+\mu-\mathrm{R}][1-\tau] \mathrm{e}^{-\mathrm{w}^{2} / 2}}{2 \pi\left[1-\rho^{2}\right]^{3 / 2}}\right\} \mathrm{dw} \\
& +\int_{[\mu-\mathrm{R}] / \sigma}^{\infty}\left\{\frac{-\mathrm{e}^{-\mathrm{J}^{2} / 2}\left[\mathrm{w}+\frac{[\mu-\mathrm{R}]}{\sigma} \rho\right][\mathrm{w} \sigma+\mu-\mathrm{R}][1-\tau] \mathrm{e}^{-\mathrm{w}^{2} / 2}}{2 \pi\left[1-\rho^{2}\right]^{3 / 2}}\right\} \mathrm{dw}
\end{aligned}
$$

It is clear that the second integral in (A-9) is strictly positive because $w \in[\{[\mu-\mathrm{R}] / \sigma\}, \infty]$ so that the integrand is unambiguously positive pointwise. As for the first integral, define $\xi_{1} \equiv[\mu-\mathrm{R}] / \sigma>0, \xi_{2} \equiv \xi_{1}[1+\rho]>0, \xi_{3} \equiv \xi_{1}^{2} \rho$, and $\xi_{4} \equiv \frac{\sigma[1-\tau]}{\sqrt{2 \pi}\left[1-\rho^{2}\right]^{3 / 2}}>0$. Then we can write the first integral in (A-9) as:

$$
\int_{[\mathrm{R}-\mu] / \sigma}^{[\mu-\mathrm{R}] / \sigma} \frac{\xi_{4} \cdot\left[\mathrm{w}^{2}+\xi_{2} \mathrm{~W}+\xi_{3}\right] \mathrm{e}^{-\mathrm{J}^{2} / 2} \mathrm{e}^{-\mathrm{w}^{2} / 2}}{\sqrt{2 \pi}} \mathrm{dw}
$$

Define $\Phi(\mathrm{w}) \equiv\left[\mathrm{w}^{2}+\xi_{2} \mathrm{w}+\xi_{3}\right] \mathrm{e}^{-\mathrm{J}^{2} / 2}$, and $\hat{\mathrm{w}} \equiv \mathrm{w} / \sqrt{1-\rho^{2}}$. Thus, $\mathrm{d} \hat{\mathrm{w}}\left[\sqrt{1-\rho^{2}}\right]=\mathrm{dw}$ and we can write the first integral in (A-9) as:

$$
\int_{[R-\mu] / \sigma \sqrt{1-\rho^{2}}}^{[\mu-\mathrm{R}] / \sigma \sqrt{1-\rho^{2}}} \frac{\xi_{4} \Phi(\hat{\mathrm{W}}) \mathrm{e}^{-\mathrm{w}^{2} / 2\left[1-\rho^{2}\right]}}{\sqrt{2 \pi}} \frac{\mathrm{d} \hat{\mathrm{w}}}{\sqrt{1-\rho^{2}}},
$$

where $\Phi(\hat{\mathrm{w}}) \equiv\left\{\hat{\mathrm{W}}^{2}\left[1-\rho^{2}\right]+\xi_{2} \hat{\mathrm{w}} \sqrt{1-\rho^{2}}+\xi_{3}\right\} \mathrm{e}^{-\hat{\mathrm{J}}^{2} / 2}$ 
and $\hat{\mathbf{J}} \equiv \frac{\{[\mathrm{R}-\mu] / \sigma\}-\rho \hat{\mathrm{w}} \sqrt{1-\rho^{2}}}{\sqrt{1-\rho^{2}}}$

Defining $\hat{\Phi}(\hat{\mathrm{w}}) \equiv\left\{\hat{\mathrm{w}}^{2}\left[1-\rho^{2}\right]+\xi_{2} \hat{\mathrm{w}} \sqrt{1-\rho^{2}}+\xi_{3}\right\}$, we see that $\hat{\Phi}(\hat{\mathrm{w}})$ is convex in $\hat{\mathrm{w}}$. We can thus write the above integral as:

$$
\begin{aligned}
& \frac{\xi_{4}}{\sqrt{1-\rho^{2}}} \int_{[\mathrm{R}-\mu] / \sigma \sqrt{1-\rho^{2}}}^{[\mu-\mathrm{R}] / \sigma \sqrt{1-\rho^{2}}} \frac{\hat{\Phi}(\hat{\mathrm{w}}) \mathrm{e}^{-\left\{\left\{\hat{\mathrm{J}}^{2} / 2\right]+\left[\hat{\mathrm{w}}^{2} / 2\left[1-\rho^{2}\right]\right]\right\}}}{\sqrt{2 \pi}} \mathrm{d} \hat{\mathrm{w}} \\
& =\frac{\xi_{4} \mathrm{e}^{\left.-\{[\mathrm{R}-\mu] / \sigma]^{2} / 2\left[1-\rho^{2}\right]\right\}}}{\sqrt{1-\rho^{2}}}\left\{\int_{[\mathrm{R}-\mu] / \sigma \sqrt{1-\rho^{2}}}^{[\mu-\mathrm{R}] / \sigma \sqrt{1-\rho^{2}}} \hat{\Phi}(\hat{\mathrm{w}}) \mathrm{e}^{-\left\{\frac{\hat{\mathrm{w}}[\mu-\mathrm{R}]}{\sigma \sqrt{1-\rho^{2}}}\right\}} \mathrm{e}^{-\hat{\mathrm{w}}^{2} / 2} \mathrm{~d} \hat{\mathrm{w}}\right\} \\
& =\xi_{4} \xi_{5} \int_{[R-\mu] / \sigma \sqrt{1-\rho^{2}}}^{[\mu-\mathrm{R}] / \sigma \sqrt{1-\rho^{2}}} \frac{\hat{\Phi}(\hat{\mathrm{W}}) \mathrm{e}^{-\hat{\mathrm{w}}^{2} / 2}}{\sqrt{2 \pi}} \mathrm{d} \hat{\mathrm{W}} \\
& >\xi_{4} \xi_{5} \Phi\left(\int_{[R-\mu] / \sigma \sqrt{1-\rho^{2}}}^{[\mu-R] / \sigma \sqrt{1-\rho^{2}}} \frac{\hat{\mathrm{W}} \mathrm{e}^{-\hat{\mathrm{w}}^{2} / 2}}{\sqrt{2 \pi}} \mathrm{d} \hat{\mathrm{W}}\right) \\
& =\xi_{4} \xi_{5} \bar{\Phi}(0)
\end{aligned}
$$

where $\bar{\Phi}(\hat{\mathrm{w}}) \equiv \hat{\Phi}(\hat{\mathrm{w}}) \mathrm{e}^{-\left\{\frac{\hat{\mathrm{w}}[\mu-\mathrm{R}]}{\sigma \sqrt{1-\rho^{2}}}\right\}}, \xi_{5} \equiv \frac{\exp \left[-\frac{\{\mathrm{R}-\mu] / \sigma\}^{2}}{2\left[1-\rho^{2}\right]}\right]}{\sqrt{1-\rho^{2}}}$ and the inequality above follows from Jensen's inequality applied to the convex function $\bar{\Phi}(\hat{\mathrm{w}})$. The last step above follows from the fact that $\hat{\mathrm{w}}$ is a mean-zero normal random variable. Note further that $\xi_{4}>0, \xi_{5}>0$ and $\bar{\Phi}(0)=\xi_{3}>0 \quad \forall \rho>0$. Thus, we have proved that $\xi_{4} \xi_{5} \bar{\Phi}(0)>0$, which implies that $\int_{[\mathrm{R}-\mu] / \sigma}^{[\mu-\mathrm{R}] / \sigma} \frac{\xi_{4}\left[\mathrm{w}^{2}+\xi_{2} \mathrm{w}+\xi_{3}\right] \mathrm{e}^{-\mathrm{J}^{2} / 2} \mathrm{e}^{-\mathrm{w}^{2} / 2}}{\sqrt{2 \pi}} \mathrm{dw}>0$.

This completes the proof that $\partial \mathrm{V}_{\mathrm{y}}(\rho, \eta) / \partial \rho>0 \forall \rho>0$ since we have established that (A-9) is strictly positive for $\rho>0$. 
Now consider $\rho<0$. Note that we can write (A-9) as:

$$
\begin{aligned}
& \int_{[\mathrm{R}-\mu] / \sigma}^{[\mu-\mathrm{R}] / \sigma} \frac{\xi_{4} \xi_{2} \mathrm{we}^{-\mathrm{J}^{2} / 2} \mathrm{e}^{-\mathrm{w}^{2} / 2}}{\sqrt{2 \pi}} \mathrm{dw}+\int_{[\mu-\mathrm{R}] / \sigma}^{[\mu-\mathrm{R}] / \sigma|\mathrm{\rho}|} \frac{\xi_{4} \xi_{2} \mathrm{we}^{-\mathrm{J}^{2} / 2} \mathrm{e}^{-\mathrm{w}^{2} / 2}}{\sqrt{2 \pi}} \mathrm{dw} \\
& +\int_{[\mathrm{R}-\mu] / \sigma}^{[\mu-\mathrm{R}] / \sigma|\rho|} \frac{\xi_{4}\left[\mathrm{w}^{2}+\xi_{3}\right] \mathrm{e}^{-\mathrm{J}^{2} / 2} \mathrm{e}^{-\mathrm{w}^{2} / 2}}{\sqrt{2 \pi}} \mathrm{dw}+\int_{[\mu-\mathrm{R}] / \sigma \rho \mid}^{\infty} \frac{\xi_{4}\left[\mathrm{w}^{2}+\xi_{2} \mathrm{~W}+\xi_{3}\right] \mathrm{e}^{-\mathrm{J}^{2} / 2} \mathrm{e}^{-\mathrm{w}^{2} / 2}}{\sqrt{2 \pi}} \mathrm{dw}
\end{aligned}
$$

It is obvious that

$$
\int_{[\mu-\mathrm{R}] / \sigma}^{[\mu-\mathrm{R}] / \sigma \mid \mathrm{p}]} \frac{\xi_{4} \xi_{2} \mathrm{we}^{-\mathrm{J}^{2} / 2} \mathrm{e}^{-\mathrm{w}^{2} / 2}}{\sqrt{2 \pi}} \mathrm{dw}>0
$$

since $w>0$ over $[\{[\mu-R] / \sigma\},[\mu-R] / \sigma|\rho|]$. Further, we can write:

$$
\begin{aligned}
& \int_{[\mathrm{R}-\mu] / \sigma}^{[\mu-\mathrm{R}] / \sigma} \frac{\xi_{4} \xi_{2} \mathrm{we}^{-\mathrm{J}^{2} / 2} \mathrm{e}^{-\mathrm{w}^{2} / 2}}{\sqrt{2 \pi}} \mathrm{dw} \\
& =\xi_{4} \xi_{2} \mathrm{E}_{\mathrm{c}}\left(\mathrm{we}^{-\mathrm{J}^{2} / 2}\right)
\end{aligned}
$$

where $\mathrm{E}_{\mathrm{c}}(\cdot)$ is the conditional expectation of a function of $\mathrm{w}$ over

$\mathrm{w} \in[\{[\mathrm{R}-\mu] / \sigma\},\{[\mu-\mathrm{R}] / \sigma\}]$, and $\xi_{2}>0, \xi_{4}>0$. Moreover,

$$
\begin{aligned}
\mathrm{E}_{\mathrm{c}}\left(\mathrm{we}^{-\mathrm{J}^{2} / 2}\right) & =\operatorname{cov}_{\mathrm{c}}\left(\mathrm{w}, \mathrm{e}^{-\mathrm{J}^{2} / 2}\right)+\mathrm{E}_{\mathrm{c}}(\mathrm{w}) \mathrm{E}_{\mathrm{c}}\left(\mathrm{e}^{-\mathrm{J}^{2} / 2}\right) \\
& =\operatorname{cov}_{\mathrm{c}}\left(\mathrm{w}, \mathrm{e}^{-\mathrm{J}^{2} / 2}\right) \text { since } \mathrm{E}_{\mathrm{c}}(\mathrm{w})=0,
\end{aligned}
$$

where $\operatorname{cov}_{c}(\cdot, \cdot)$ is the conditional covariance, given $w \in[\{[R-\mu] / \sigma\},\{[\mu-R] / \sigma\}]$. Now

$$
\begin{aligned}
\partial \mathrm{e}^{-\mathrm{J}^{2} / 2} / \partial \mathrm{w} & =\frac{-\left[\rho \mathrm{w}+\xi_{1}\right] \mathrm{e}^{-\mathrm{J}^{2} / 2} \rho}{\left[1-\rho^{2}\right]} \\
& >0 \text { when } \rho<0 \text { since } \xi_{1}>w .
\end{aligned}
$$

This means that $\operatorname{cov}_{\mathrm{c}}\left(\mathrm{w}, \mathrm{e}^{-\mathrm{J}^{2} / 2}\right)>0$, which implies that $\xi_{4} \xi_{2} \mathrm{E}_{\mathrm{c}}\left(\mathrm{we}^{-\mathrm{J}^{2} / 2}\right)>0$. Having shown that the first two terms in (A-10) are positive, we now turn to the third term, which can be written as: 
$\int_{[\mathrm{R}-\mu] / \sigma}^{[\mu-\mathrm{R}] / \sigma|\rho|}\left\{\frac{\xi_{4}\left[\mathrm{w}^{2}-|\rho|\left\{\frac{\mu-\mathrm{R}}{\sigma}\right\}^{2}\right] \mathrm{e}^{-\mathrm{J}^{2} / 2} \mathrm{e}^{-\mathrm{w}^{2} / 2}}{\sqrt{2 \pi}}\right\} \mathrm{dw}$

Now,

$$
\begin{aligned}
\partial \mathrm{e}^{-\mathrm{J}^{2} / 2} / \partial \mathrm{w} & =\frac{\mathrm{J} \rho \mathrm{e}^{-\mathrm{J}^{2} / 2}}{\sqrt{1-\rho^{2}}} \\
& >0 \text { if } \mathrm{J}<0 .
\end{aligned}
$$

Since $w<[\mu-R] / \sigma|\rho|$ in the integral above, and $\rho<0$, we know that $J<0$. Hence, $\mathrm{e}^{-\mathrm{J}^{2} / 2}$ is strictly increasing in $w \forall \rho \in(-1,0)$. Given this and the fact that $\mathrm{w}^{2}$ is increasing in $\mathrm{w}$, we can write:

$\int_{[\mathrm{R}-\mu] / \sigma}^{[\mu-\mathrm{R}] / \sigma|\rho|}\left\{\frac{\xi_{4}\left[\mathrm{w}^{2}-|\rho|\left\{\frac{\mu-\mathrm{R}}{\sigma}\right\}^{2}\right] \mathrm{e}^{-\mathrm{J}^{2} / 2} \mathrm{e}^{-\mathrm{w}^{2} / 2}}{\sqrt{2 \pi}}\right\} \mathrm{dw}$

$>\int_{[\mathrm{R}-\mu] / \sigma}^{[\mu-\mathrm{R}] / \sigma|\rho|}\left\{\frac{\xi_{4}\left[\left\{\frac{\mu-\mathrm{R}}{\sigma}\right\}^{2}-|\rho|\left\{\frac{\mu-\mathrm{R}}{\sigma}\right\}^{2}\right] \mathrm{e}^{-\mathrm{J}^{2} / 2} \mathrm{e}^{-\mathrm{w}^{2} / 2}}{\sqrt{2 \pi}}\right\} \mathrm{dw}$

$>0 \quad \forall \rho \in(-1,0)$.

As for the fourth term in (A-10), we can write it in its original form (see (A-9)) as:

$\int_{[\mu-R] / \sigma|\rho|}^{\infty}\left\{\frac{\mathrm{e}^{-\mathrm{J}^{2} / 2}\left[\mathrm{w}+\frac{[\mu-\mathrm{R}]}{\sigma} \rho\right][\mathrm{w} \sigma+\mu-\mathrm{R}][1-\tau] \mathrm{e}^{-\mathrm{w}^{2} / 2}}{\sqrt{2 \pi}}\right\} \mathrm{dw}$ 
Since the integrand is unambiguously positive pointwise $\forall \mathrm{w}>[\mu-\mathrm{R}] / \sigma|\rho|$, we see that the above integral is strictly positive. Thus, we have proved that (A-10) is strictly positive, which means (A-9) is strictly positive for $\rho<0$.

Proof of Lemma 1: Very similar to that of Theorem 2 and therefore omitted to conserve space.

Proof of Lemma 2: If the firm issues debt at $t=1$, then at $t=2$ bondholders have the right to veto any project choice by the firm. If the mundane project is chosen, the payoff at $t=3$ is $R$, which is non-stochastic, and R > I, which means debt is riskless and bondholders' expected payoff is I. If the innovative project is chosen and the bondholders assess its value at $t=1$ as $y$, then they will assess their expected payoff as

$$
\int_{-\infty}^{\mathrm{I}}[\mathrm{y}+\widetilde{\varepsilon}] \psi(\widetilde{\varepsilon}) \mathrm{d} \widetilde{\varepsilon}+\int_{\mathrm{I}}^{\infty} \mathrm{I} \psi(\widetilde{\varepsilon}) \mathrm{d} \widetilde{\varepsilon}<\mathrm{I} \forall \mathrm{y}<\infty
$$

where $\psi(\widetilde{\varepsilon})$ is the density function of $\widetilde{\varepsilon}$. Thus, bondholders will veto the innovative project for any finite y i.e., almost surely. Given that, the mundane project will be chosen by management at $\mathrm{t}=2$, and anticipating this, the stock price at $\mathrm{t}=1$ will be the NPV of the mundane project, $[\mathrm{R}-\mathrm{I}][1-\tau]$.

Proof of Theorem 3: The expected terminal $(t=3)$ wealth of those who are shareholders at $t=0$, as assessed by management when equity financing is used, is given by (4). Equity is preferred to debt if $V_{x}(\rho, \eta)$ exceeds the value with debt, which is [R-I] [1- $\left.\tau\right]$. Now $V_{x}(\rho, \eta)$ is minimized at $\rho=-1$ (see Lemma 1). Thus,

$$
\begin{aligned}
\mathrm{V}_{\mathrm{x}}(-1, \eta) & =\int_{\mathrm{R}}^{\mu+[\mu-\mathrm{R}]} \mathrm{x}[1-\tau] \mathrm{g}(\mathrm{x} \mid-1) \mathrm{dx}+\int_{-\infty}^{\mathrm{R}} \mathrm{R}[1-\tau] \mathrm{h}(\mathrm{y} \mid-1) \mathrm{dy} \\
& +\int_{-\infty}^{\mathrm{R}} \mathrm{R}[1-\tau] \mathrm{g}(\mathrm{x} \mid-1) \mathrm{dx}+\eta \int_{\mu+[\mu-\mathrm{R}]}^{\infty}[\mathrm{x}-\mathrm{R}][1-\tau] \mathrm{g}(\mathrm{x} \mid-1) \mathrm{dx}-\mathrm{I}
\end{aligned}
$$


Now substitute

$$
\int_{-\infty}^{\mathrm{R}} \mathrm{h}(\mathrm{y} \mid-1) \mathrm{dy}=\int_{\mu+[\mu-\mathrm{R}]}^{\infty} \mathrm{g}(\mathrm{x} \mid-1) \mathrm{dx}
$$

to get

$$
\begin{aligned}
V_{x}(-1, \eta) & =\int_{R}^{\mu+[\mu-R]} x[1-\tau] g(x \mid-1) d x+\int_{\mu+[\mu-R]}^{\infty} R[1-\tau] g(x \mid-1) d x \\
& +\int_{-\infty}^{R} R[1-\tau] g(x \mid-1) d x+\eta \int_{\mu+[\mu-R]}^{\infty}[x-R][1-\tau] g(x \mid-1) d x-I
\end{aligned}
$$

For equity to dominate, we need

$\mathrm{V}_{\mathrm{x}}(-1, \eta)>[\mathrm{R}-\mathrm{I}][1-\tau]$

If $\eta=1$, substituting $(\mathrm{A}-11)$ in $(\mathrm{A}-12)$ yields

$$
\int_{R}^{\infty} x g(x \mid-1) d x-\int_{R}^{\infty} R g(x \mid-1) d x>\frac{\tau I}{1-\tau}
$$

We can write this as (use $\mu=\int_{-\infty}^{\infty} \mathrm{x} g(\mathrm{x} \mid-1) \mathrm{dx}$ ),

$\mu>\mathrm{R}+\frac{\tau \mathrm{I}}{1-\tau}-\left\{\int_{-\infty}^{\mathrm{R}} \mathrm{R} \mathrm{g}(\mathrm{x} \mid-1) \mathrm{dx}-\int_{-\infty}^{\mathrm{R}} \mathrm{xg}(\mathrm{x} \mid-1) \mathrm{dx}\right\}$

Since $\left\{\int_{-\infty}^{R} R g(x \mid-1) d x-\int_{-\infty}^{R} x g(x \mid-1) d x\right\}>0$,

the condition given below is sufficient for the above inequality to hold:

$\mu>\mathrm{R}+\frac{\mathrm{I} \tau}{[1-\tau]}$

which we know is satisfied given (3). Thus, (A-13) holds.

This means that $V_{x}(\rho, 1)>[R-I][1-\tau] \forall \rho$. By continuity of $V_{x}(\rho, \eta)$ in $\eta$, we know that $\mathrm{V}_{\mathrm{x}}(\rho, \eta)>[\mathrm{R}-\mathrm{I}][1-\tau]$ in a neighborhood of $\eta=1$. Inspection of $(\mathrm{A}-12)$ reveals that debt 
strictly dominates equity if $\eta=0$ and $\rho=-1$. By continuity of $V_{x}(\rho, \eta)$ in $\rho$ and $\eta$, we know now that $\exists \eta^{*} \in(0,1)$ such that equity is strictly preferred to debt for all $\eta>\eta^{*}$. For $\eta \leq \eta^{*}$, debt may be preferred depending on $\rho$. And since $\partial \mathrm{V}_{\mathrm{x}}(\rho, \eta) / \partial \rho>0$, we have shown that for $\eta \leq \eta^{*}, \exists$ a critical value $\rho^{*}(\eta)$ such that management prefers to issue equity for $\rho \geq \rho^{*}(\eta)$ and debt if $\rho<\rho^{*}(\eta)$

Proof of Theorem 4: Suppose $\eta<\eta^{*}$. Also suppose $\rho \geq \rho^{*}(\eta)$. Then in the conjectured Nash equilibrium, the market believes the firm will issue equity. It thus sets the pre-equity-issuance stock price of the firm at $\mathrm{V}_{\mathrm{y}}(\rho, \eta)$. Because $\partial \mathrm{V}_{\mathrm{y}}(\rho, \eta) / \partial \rho>0$, we know that $\mathrm{V}_{\mathrm{y}}(\rho, \eta):[0,1] \times$ $[0,1] \rightarrow \mathrm{R}^{+}$is one-to-one in $\rho$ and invertible (here $\mathrm{R}^{+}$is the non-negative real line). Management can thus observe $V_{y}(\rho, \eta)$ and correctly infer $\rho$. Given its knowledge of $\rho$, management recognizes that $\rho \geq \rho^{*}(\eta)$ and thus finds it optimal to issue equity. This is consistent with the market's beliefs about what the firm will do.

Now suppose $\rho<\rho^{*}(\eta)$. In the conjectured Nash equilibrium, the market believes the firm will issue debt. It thus sets the pre-debt-issuance stock price of the firm at $[R-I][1-\tau]$. Observing this stock price does not allow management to learn the precise value of $\rho$, but it infers that $\rho<\rho^{*}(\eta)$. For these values of $\rho$, it is optimal for management to issue debt, thereby confirming the market's beliefs.

Proof of Corollary 1: It follows from (4) that $\partial \mathrm{V}_{\mathrm{x}}(\rho, \eta) / \partial \eta>0$. Now consider two values of $\eta, \eta_{0}$ and $\eta_{1}$ with $\eta_{0}<\eta_{1}$. Let $\rho^{*}\left(\eta_{0}\right)$ be the cutoff with $\eta_{0}$. That is,

$$
\mathrm{V}_{\mathrm{x}}\left(\rho^{*}\left(\eta_{0}\right), \eta_{0}\right)=[\mathrm{R}-\mathrm{I}][1-\tau] \text {. }
$$

But since $\partial V_{x}(\rho, \eta) / \partial \eta>0$, we know that:

$$
\mathrm{V}_{\mathrm{x}}\left(\rho^{*}\left(\eta_{0}\right), \eta_{1}\right)>[\mathrm{R}-\mathrm{I}][1-\tau] \text {. }
$$

Since 


$$
\mathrm{V}_{\mathrm{x}}\left(\rho^{*}\left(\eta_{1}\right), \eta_{1}\right)=[\mathrm{R}-\mathrm{I}][1-\tau]
$$

and $\partial \mathrm{V}_{\mathrm{x}}(\rho, \eta) / \partial \rho>0$, we see from (A-14) and (A-15) that:

$$
\rho^{*}\left(\eta_{1}\right)<\rho^{*}\left(\eta_{0}\right) \text {. }
$$

Proof of Corollary 2: Following steps similar to those in the proof of Theorem 2, we can establish that $\partial \mathrm{V}_{\mathrm{x}}(\rho, \eta) / \partial \sigma_{\mathrm{x}}>0$ (steps available upon request). From the proof of Theorem 3, we know that $\mathrm{V}_{\mathrm{x}}\left(\rho, \eta^{*}\right)=[\mathrm{R}-\mathrm{I}][1-\tau]$. By the continuity of $\mathrm{V}_{\mathrm{x}}(\rho, \eta)$ in $\eta$, with $\partial \mathrm{V}_{\mathrm{x}}(\rho, \eta) / \partial \eta>0$ (see (4)), we have $d \eta^{*} / d \sigma_{x}<0$. For $\eta<\eta^{*}, \rho^{*}$ is defined such that $V_{x}\left(\rho^{*}, \eta\right)=[R-I][1-\tau]$. By the continuity of $V_{x}(\rho, \eta)$ in $\rho$, with $\partial V_{x}(\rho, \eta) / \partial \rho<0$ and $\partial V_{x}(\rho, \eta) / \partial \sigma_{x}>0$, we have $d \rho^{*} / d \sigma_{x}$ $<0$.

Proof of Corollary 3: Immediate upon inspecting (A-5).

Proof of Theorem 5: The statement of the theorem assumes $\eta<\eta^{*}$. We know that equity will be issued at $t=1$ if a project is available and if $\rho \geq \rho^{*}(\eta)$. At $t=0$, we know from (5) that the stock price $\mathrm{V}_{\mathrm{y}}^{0}(\rho, \eta, \theta)$ is increasing in $\theta$. The maximum stock price at $\mathrm{t}=0$, conditional on a debt issue at $t=1$, is $[R-I][1-\tau]$. So once the stock price rises above $\hat{V}_{y}^{0} \equiv[R-I][1-\tau]$, we know at $t=0$ that $\rho>\rho^{*}$ almost surely and equity will be issued at $t=1$. Conditional on equity being issued, an increase in the stock price beyond $\hat{\mathrm{V}}_{\mathrm{y}}^{0}$ conveys the joint information about the twodimensional random variable $(\theta, \rho)$, and it implies higher values of $\theta$. To see this, note from (5) that for $\mathrm{V}_{\mathrm{y}}^{0}(\rho, \eta, \theta)>[\mathrm{R}-\mathrm{I}][1-\tau]$ and $\eta<\eta^{*}$, we can write

$$
\mathrm{V}_{\mathrm{y}}^{0}(\rho, \eta, \theta)=\theta \mathrm{V}_{\mathrm{y}}(\rho, \eta)
$$

Now having observed a particular stock price at $\mathrm{t}=0$, say $\hat{\mathrm{V}}_{\mathrm{y}}^{0}$, the econometrician can infer $\theta$ (let the inferred $\theta$ be called $\hat{\theta}$ ) as follows for every possible $\rho$ : 


$$
\hat{\theta}\left(\rho \mid \hat{\mathrm{V}}_{\mathrm{y}}^{0}\right)=\frac{\hat{\mathrm{V}}_{\mathrm{y}}^{0}}{\mathrm{~V}_{\mathrm{y}}(\rho, \eta)}
$$

where $\eta$ is common knowledge and fixed. The probability of equity issuance is now the expectation of $\hat{\theta}$ taken over $\rho$, i.e.,

$$
\mathrm{E}\left(\hat{\theta}\left(\rho \mid \hat{\mathrm{V}}_{\mathrm{y}}^{0}\right)\right)=\int_{\rho^{*}}^{1} \hat{\theta}\left(\rho \mid \hat{\mathrm{V}}_{\mathrm{y}}^{0}\right) \Phi(\rho) \mathrm{d} \rho
$$

where $\Phi(\bullet)$ is the probability density function of $\rho$. Note that $\partial \hat{\theta}\left(\rho \mid \hat{\mathrm{V}}_{\mathrm{y}}^{0}\right) / \partial \hat{\mathrm{V}}_{\mathrm{y}}^{0}>0$, so the integral in (A-17) is increasing pointwise in $\hat{\mathrm{V}}_{\mathrm{y}}^{0}$. Thus,

$$
\partial \mathrm{E}\left(\hat{\theta}\left(\rho \mid \hat{\mathrm{V}}_{\mathrm{y}}^{0}\right)\right) / \partial \hat{\mathrm{V}}_{\mathrm{y}}^{0}>0 .
$$

Proof of Corollary 4: All firms with $\rho>\rho^{*}(\eta)$ issue equity and all firms with $\rho \leq \rho^{*}(\eta)$ issue debt, conditional on a project being available (see Theorem 3). It follows immediately that the number of firms issuing equity is increasing in the likelihood of future growth opportunities, $\theta$. Since $\partial V_{x}(\rho, \eta) / \partial \mu>0$ and $\rho^{*}(\eta)$ solves $V_{x}\left(\rho^{*}(\eta), \eta\right)=[R-I][1-\tau]$, it follows that $\partial \rho^{*}(\eta) / \partial \mu<0$. Hence, an increase in $\mu$ strictly increases the number of firms for which $\rho>\rho^{*}(\eta)$, leading to more equity issues being observed. 


\section{REFERENCES}

Allen, Franklin and Douglas Gale, "Diversity of Opinion and Financing of New Technologies", Journal of Financial Intermediation 8, 1999, pp. 68-89.

Allen, Franklin, and Douglas Gale, Financial Innovation and Risk Sharing, MIT Press, Cambridge, Massachusetts, 2000.

Antoniou, Antonios, Yilmaz Guney, and Krishna Paudyal, "Determinants of Corporate Capital Structure: Evidence from European Countries", Working Paper, University of Durham, March 1, 2002.

Asquith, Paul and David W. Mullins, "Equity Issues and Offering Dilution", Journal of Financial Economics 15, 1986, pp. 61-89.

Baker, Malcolm and Jeffrey Wurgler, "Market Timing and Capital Structure", Journal of Finance 57, 2002, pp. 1-32.

Barclay, Michael, J., Clifford W. Smith and Ross L. Watts, "The Determinants of Corporate Leverage and Dividend Policies", Journal of Applied Corporate Finance 7, 1995, pp. 419.

Berlin, Mitchell and Loretta J. Mester, "Debt Covenants and Renegotiation", Journal of Financial Intermediation 2, 1992, pp. 95-133.

Boot, Arnoud W.A. and Anjan V. Thakor, "Financial System Architecture", Review of Financial Studies 10, 1997, pp. 693-733.

Boot, Arnoud W.A. and Anjan V. Thakor, "The Economic Value of Flexibility When There is Disagreement", Working Paper, University of Michigan Business School, November 2002.

Brander, James A. and Tracy R. Lewis, "Oligopoly and Financial Structure: The Limited Liability Effect”, American Economic Review 76, 1986, pp. 956-970.

Clarke, Ian and William Mackaness, "Management 'Intuition': An Interpretative Account of Structure and Content of Decision Schemas Using Cognitive Maps", Journal of Management Studies 38, 2001, pp. 147-172.

Daniel, Kent, David Hirshleifer and Avanidhar Subrahmanyam, "Investor Psychology and Security Market Under- and Over-Reactions", Journal of Finance 53, 1998, pp. 18391886.

Daniel, Kent, David Hirshleifer and Avanidhar Subrahmanyam, "Overconfidence, Arbitrage, and Equilibrium Asset Pricing,” Journal of Finance 56, 2001, pp. 921-965

DeAngelo, Harry and Ronald Masulis, "Optimal Capital Structure under Corporate and Personal Taxation", Journal of Financial Economics 8, 1980, pp. 3-29. 
Denis, David J. and Atulya Sarin, "Is the Market Surprised by Poor Earnings Realizations Following Seasoned Equity Offering?", Journal of Financial and Quantitative Analysis 36, 2001, pp. 169-193.

Flannery, Mark and Kasturi Rangan, "Market Forces at Work in the Banking Industry: Evidence from the Capital Buildup of the 1990s", Working Paper, University of Florida, February 2002.

Fulghieri, Paolo and Dmitry Lukin, "Information Production, Dilution Costs, and Optimal Security Design", Journal of Financial Economics 61, 2001, pp. 3-42.

Goyal, Vidhan, K., Kenneth Lehn and Stanko Racic, "Growth Opportunities and Corporate Debt Policy: the Case of the U.S. Defense Industry", Journal of Financial Economics 64, 2002, pp. 35-59.

Graham, John R. and Campbell R. Harvey, "The Theory and Practice of Corporate Finance: Evidence from the Field", Journal of Financial Economics 60, 2001, pp. 187-243.

Grossman, Sanford and Oliver Hart, "Corporate Financial Structure and Managerial Incentives", in J. McCall, ed.: The Economics of Information and Uncertainty, University of Chicago Press, Chicago, 1982.

Hirshleifer, David, Seongyeon Lim and Siew Hong Teoh, "Disclosure to a Credulous Audience: The Role of Limited Attention", Working Paper, Ohio State University, February 2002.

Hovakimian, Armen, Tim C. Opler and Sheridan Titman, "The Debt-Equity Choice", Journal of Financial and Quantitative Analysis 36, 2001, pp. 1-24.

Jaggia, Priscilla and Anjan V. Thakor, "Firm-Specific Human Capital and Optimal Capital Structure", International Economic Review 35, 1994, pp. 283-308.

Jensen, Michael C. and William Meckling, "Theory of the Firm: Managerial Behavior, Agency Costs and Ownership Structure", Journal of Financial Economics 3, 1976, pp. 305-360.

Jensen, Michael C., "Agency Costs of Free-cash-flow, Corporate Finance, and Takeovers", American Economic Review 76, 1986, pp. 323-329.

Jung, Kooyul, Yong Cheol Kim and Rene M. Stulz, "Timing, Investment Opportunities, Managerial Discretion, and the Security Issue Decision”, Journal of Financial Economics 42, 1996, pp. 159-185.

Kahneman, Daniel and Dan Lovallo, "Timid Choices and Bold Forecasts: A Cognitive Perspective on Risk-Taking”, Management Science 39, 1993, pp. 17-31.

Kandel, Eugene and Neil D. Pearson, "Differential Interpretation of Public Signals and Trade in Speculative Markets”, Journal of Political Economy 103, 1995, pp 831-872. 
Korajczyk, Robert, Deborah Lucas and Robert McDonald, "The Effect of Information Releases on the Pricing and Timing of Equity Issues", Review of Financial Studies 4, 1991, pp. 685-708.

Loughran, Tim and Jay Ritter, "The Operating Performance of Firms Conducting Seasoned Equity Offerings", Journal of Finance 52, 1997, pp. 1823-1850.

Marsh, Paul, "The Choice Between Equity and Debt: An Empirical Study", Journal of Finance 37, 1982, pp. 121-144.

Modigliani, Franco and Merton H. Miller, "The Cost of Capital, Corporation Finance, and the Theory of Investment", American Economic Review 48, 1958, pp. 655-669.

Modigliani, Franco and Merton H. Miller, "Corporate Income Taxes and the Cost of Capital: A Correction”, American Economic Review 53, 1963, pp. 433-443.

Morris, Stephen E., "The Common Prior Assumption in Economic Theory", Economics and Philosophy 11, 1995, pp. 227-253.

Mullainathan, Sendhil and Andrei Shleifer, "Media Bias", NBER Working Paper 9295, October 2002.

Myers, Stewart and Nicholas Majluf, "Corporate Financing and Investment Decisions When Firms Have Information That Investors Do Not Have", Journal of Financial Economics 13, 1984, pp. 187-221.

Opler, Tim, C. and Sheridan Titman, "Financial Distress and Corporate Performance", Journal of Finance 49, 1994, pp. 1015-1040.

Ozkan, Aydin and Neslihan Ozkan, "Corporate Cash Holding: An Empirical Investigation of U.K. Companies”, Working Paper, University of York, 2002.

Rajan, Raghuram, G. and Luigi Zingales, "Is there an Optimal Capital Structure? Some Evidence from International Data", Journal of Finance 50, 1995, pp 1421-1460.

Rajan, Raghuram, G. and Henri Servaes, "Analyst Following of Initial Public Offerings", Journal of Finance 50, 1997, pp. 507-529.

Ross, Stephen, "The Economic Theory of Agency: The Principal's Problem", American Economic Review 63, 1973, pp 134-139.

Ross, Stephen, "The Determinants of Financial Structure: The Incentive-Signaling Approach", The Bell Journal of Economics 8, 1977, pp. 23-40.

Ross, Stephen, "Equilibrium and Agency - Inadmissable Agents in the Public Agency Problem", American Economic Review 69, 1979, pp. 308-312. 
Russo, J. Edward and Paul J.H. Schoemaker, Decision Traps: Ten Barriers to Brilliant Decision-Making and How to Overcome Them, 1st Fireside ed., Simon \& Schuster, New York, 1990.

Shleifer, Andrei and Daniel Wolfenzon, "Investor Protection and Equity Markets", Journal of Financial Economics 66, 2002, pp. 3-27.

Stumpf, Steve A. and Roger L.M. Dunbar, "The Effects of Personality Type on Choice Made in Strategic Decision Situations", Decision Sciences 22, 1991, pp. 1047-1072.

Subrahmanyam, Avanidhar and Sheridan Titman, "Feedback from Stock Prices to Cash Flows", Journal of Finance 56, 2001, pp. 2389-2413.

Teoh, Siew Hong, Ivo Welch, and T. J. Wong, "Earnings Management and the Long-run Market Performance of Initial Public Offerings", Journal of Finance 53, 1998a, pp. 1935-1974.

Teoh, Siew Hong, Ivo Welch, and T. J. Wong, "Earnings Management and the Underperformance of Seasoned Equity Offerings", Journal of Financial Economics 50, 1998b, pp. 63-99.

Welch, Ivo, "Columbus's Egg: Stock Returns are the Main Determinant of Capital Structure Dynamics", Yale ICF Working Paper No. 02-03, July 26, 2002.

Zwiebel, Jeffrey, "Dynamic Capital Structure under Managerial Entrenchment", American Economic Review 86, 1996, pp. 1197-1215. 
Figure 1: Sequence of events

time

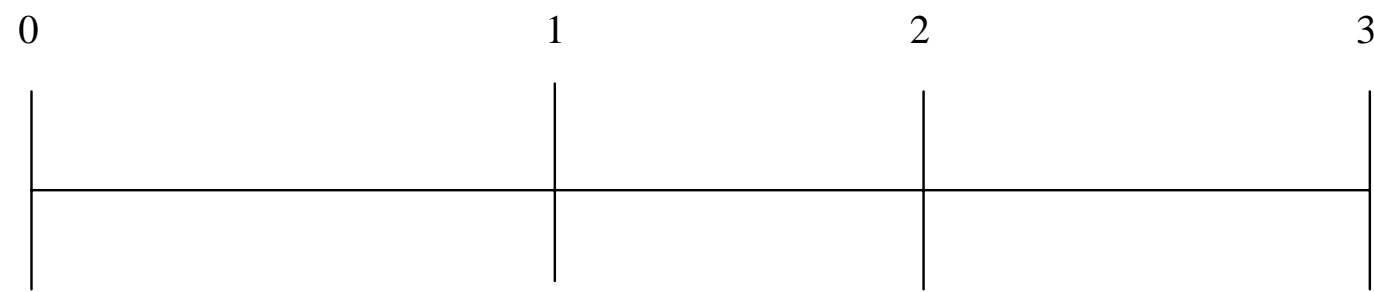

- Firm has existing activities that produce deterministic output at $\mathrm{t}=3$, which is normalized to zero.

- Existing activities are equity financed (share price is observed).
- New project (mundane or innovative) becomes available with probability $\theta$.

- Investment needed is I. Market's assessment of $\rho$ (level of agreement over future project payoffs) can be inferred from the share price.

- Firm chooses to issue debt or equity to finance the project if the project is available.
- Management observes $\mathrm{x}$ and the market observes its assessment y. These are assessments of the expected value of the payoff of the innovative project at $\mathrm{t}=3$.

- Actual project choice is made. Investors may seek to veto if innovative project is chosen.
- Payoff is realized.

- Financiers are paid if payoff permits. 
Figure 2: Relationship of Stock Price and Equity Issuance to the Agreement Parameter

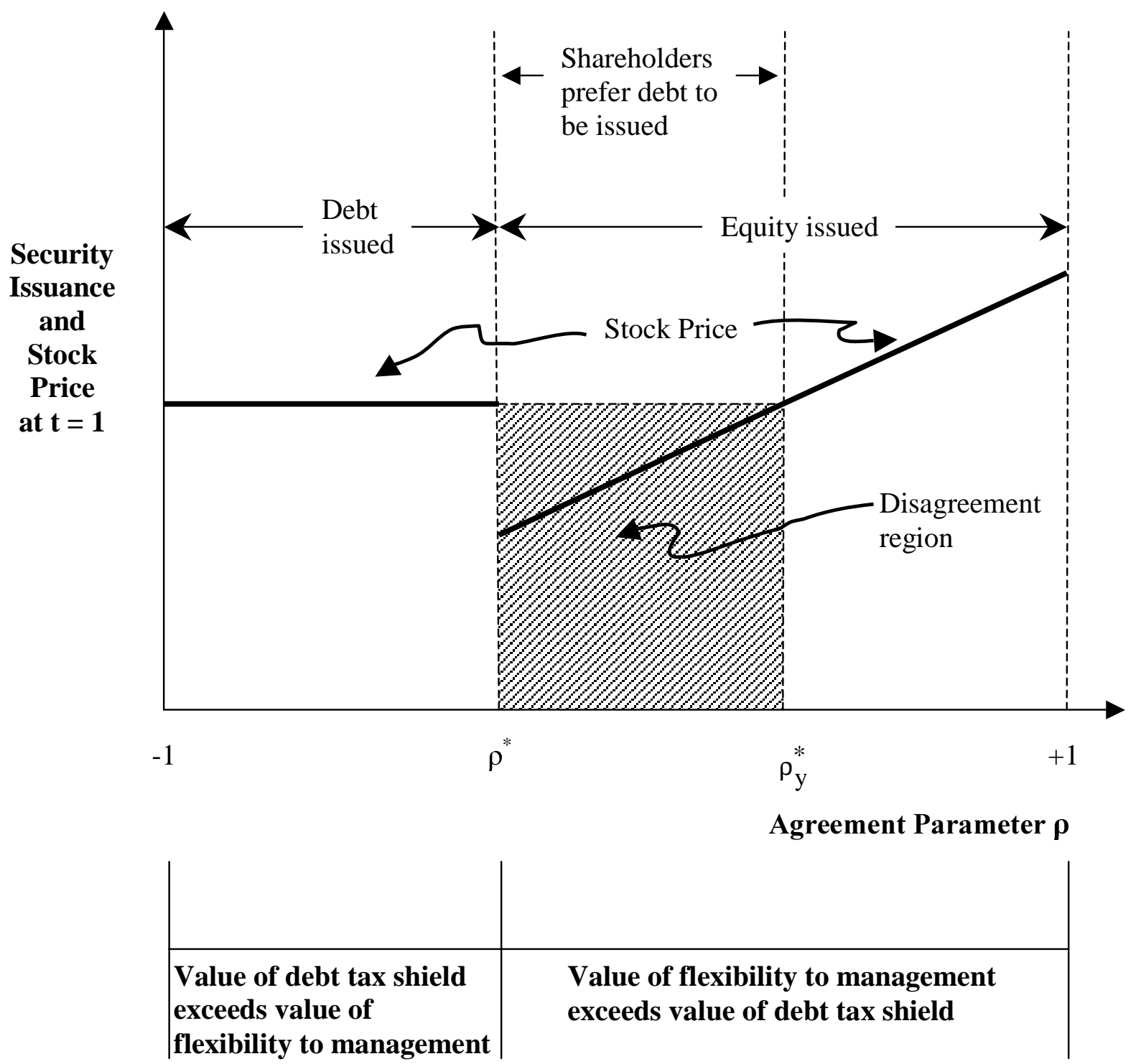

